\title{
An Investigation of Using a Phase-Change Material To Improve The \\ Heat Transfer in a Small Electronic Module For an Airborne Radar Application
}

\author{
Keith W. Snyder \\ Electronic Development Division II \\ Sandia National Laboratories \\ Albuquerque, New Mexico 87185
}

\begin{abstract}
Finding new and improved mearıs of cooling small electronic packages are of great importance to today's electronic packaging engineer. Thermal absorption through the use of a material which changes phase is an attractive alternative. Taking advantage of the heat capacity of a material's latent heat of fusion is shown to absorb heat away from the electronics, thus decreasing the overall temperature rise of the system. The energy equation is formulated in terms of enthalpy and discretized using a finite-difference method. A FORTRAN program to solve the discretized equations is presented which can be used to analyze heat conduction in a rectangular region undergoing an isothermal phase change. An analysis of heat transfer through a miniature radar electronic module cooled by a phasechange reservoir is presented, illustrating the method's advantages over conventional heat sinks.




\section{CONTENTS}

Introduction

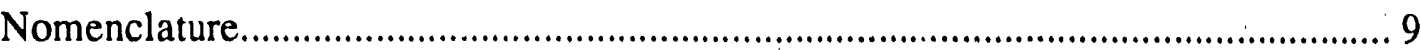

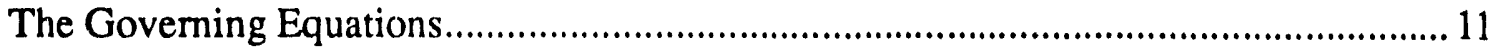

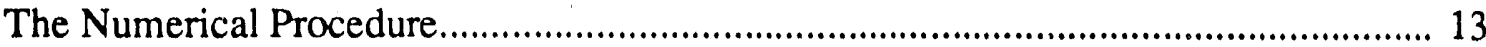

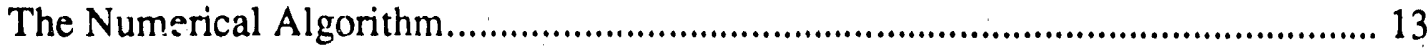

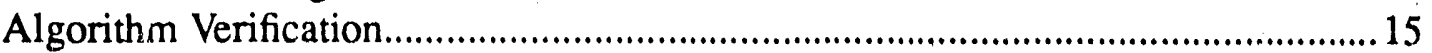

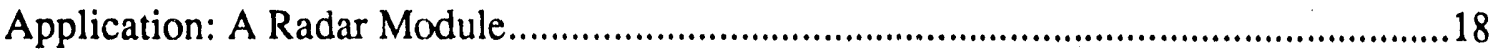

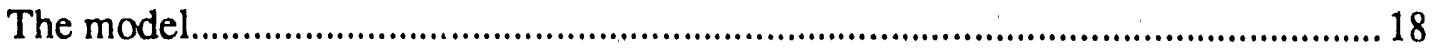

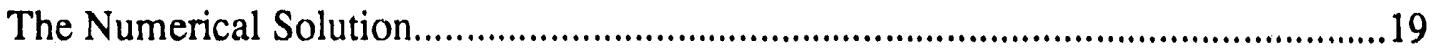

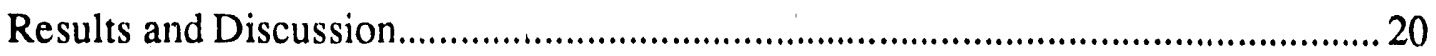

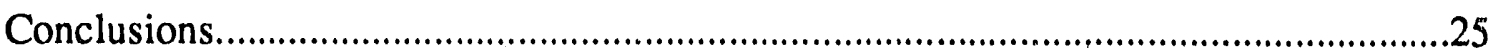

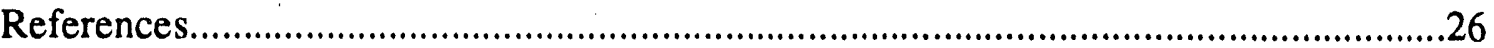

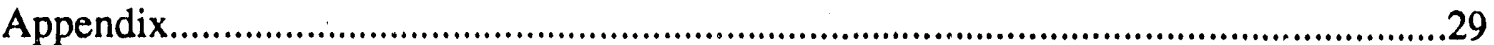

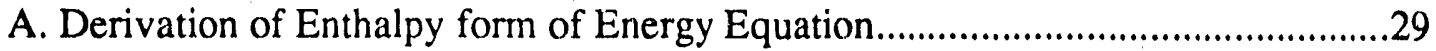

B. Discretization of Enthalpy form of Energy Equation......................................... 32

C. Determination of Aluminum Enhanced PCM Thermal Conductivity.....................34

C. Fortran Program Listings........................................................................ 36

\section{Figures}

1 Radar Electronic Module Design....................................................................... 8

2 Flowchart illustrating numerical updating of latent heat sink term..........................14

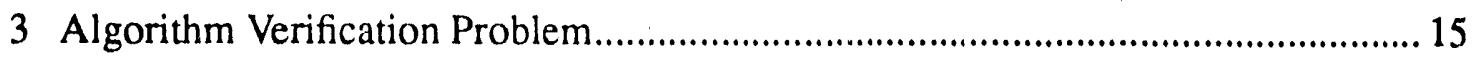

4 Verification Problem Temperature Profile at $t=500 \mathrm{~s}$............................................ 16

5 PCM Model Module Configuration.................................................................... 18

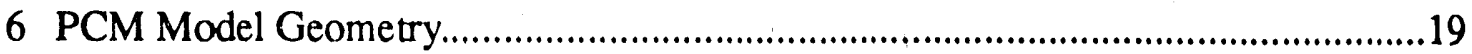

7 Application Temperature Profiles, $\mathrm{q}^{\prime \prime}=15000 \mathrm{~W} / \mathrm{m}^{2}$, Aluninum............................22

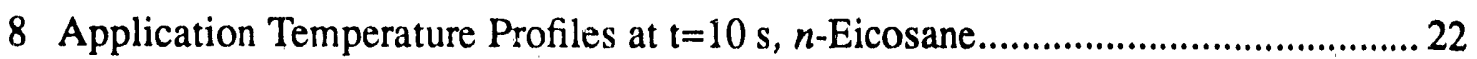

9 Application Temperature Profiles, $q^{\prime \prime}=15000 \mathrm{~W} / \mathrm{m}^{2}$,

Aluminum Enhanced $n$-Eicosane.

10 Application Temperature Profiles, $\mathrm{q}^{\prime \prime}=15000 \mathrm{~W} / \mathrm{m}^{2}$,

Aluminum Enhanced $n$-Octadecane

11 Application Temperature Profiles, $q^{\prime \prime}=30000 \mathrm{~W} / \mathrm{m}^{2}$,

Aluminum Enhanced $n$-Octadecane

\section{Tables}

1 Material Properties of $n$-Octadecane and $n$-Eicosane .........................................220

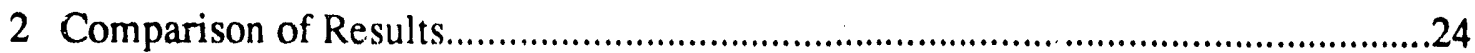




\section{INTRODUCTION}

As microelectronic components continue to get smaller with the application of modern technology, packaging gets denser and consequently heat fluxes rise. Since the author is a mechanical engineer in the radar department at Sandia National Laboratories, this investigation is directed toward finding improved cooling methods for these denser packages.

In designing packaging for radar systems, a mechanical engineer is concerned with size, weight, geometric configuration, durability, and efficient heat transfer. Most of the radars that are designed at Sandia are used in small airborne vehicles where space is limited. The radar (and radar antenna) is usually confined to a specific area in the vehicle as well. Radars are also getting more complex, such as the state-of-the-art synthetic aperture radar, which has increased both their size and power output. This increased power output directly influences the heat generated by the electronics, thus increasing the total heat flow rate.

A package for a synthetic aperture radar antenna has been designed at Sandia which includes eighty plug-in miniature electronic modules. The modules are approximately 2.5 in. $x 1.25$ in. $x .375$ in. thick with electronic components mounted on both sides of a center plate or web (See Fig. 1). Each module dissipates approximately 15 watts and is cooled in actual operation by conducting the heat away from the electronics into the aluminum body of the module. This module was designed for a specific application; however, this type of plug-in electronic package will be used in a growing number of applications in the future, such as a mapping satellite or other advanced radai's. Also as technology advances and radars and other airborne electronic subsystems become even more complex, this type of package will use more power and dissipate even more heat. Most modules of this type are operated for a short time interval (10-20 seconds) and not in a steady state mode. Thus when analyzing the heat flow, it is the transient heat transfur that is of concern to the mechanical designer.

This paper investigates a method to improve the transient heat transfer away from the electronics in this type of module. The module, as designed, has a cavity on each side of the center web. After the electronic components are mounted on each side on the center web, these two cavities are hermetically sealed to protect the sensitive electronics. The only path currently used for heat transfer is conduction into and through the aluminum center web. However, if one cavity was filled with a substance that would undergo a solidliquid phase change upon reaching a certain temperature, while the other cavity contained the electronics, or if the phase-change material were sandwiched in a cavity between the other two cavities, the heat transfer away from the electronics might be improved. Since the module's operating time is typicaily short, taking advantage of a material's latent heat of fusion should absorb the heat and keep the electronic components cooler than by conducting the heat into the body of the module. This paper details the analysis of the improvement in heat transfer effected by filling a cavity with a material that would undergo a fusion phase change. 

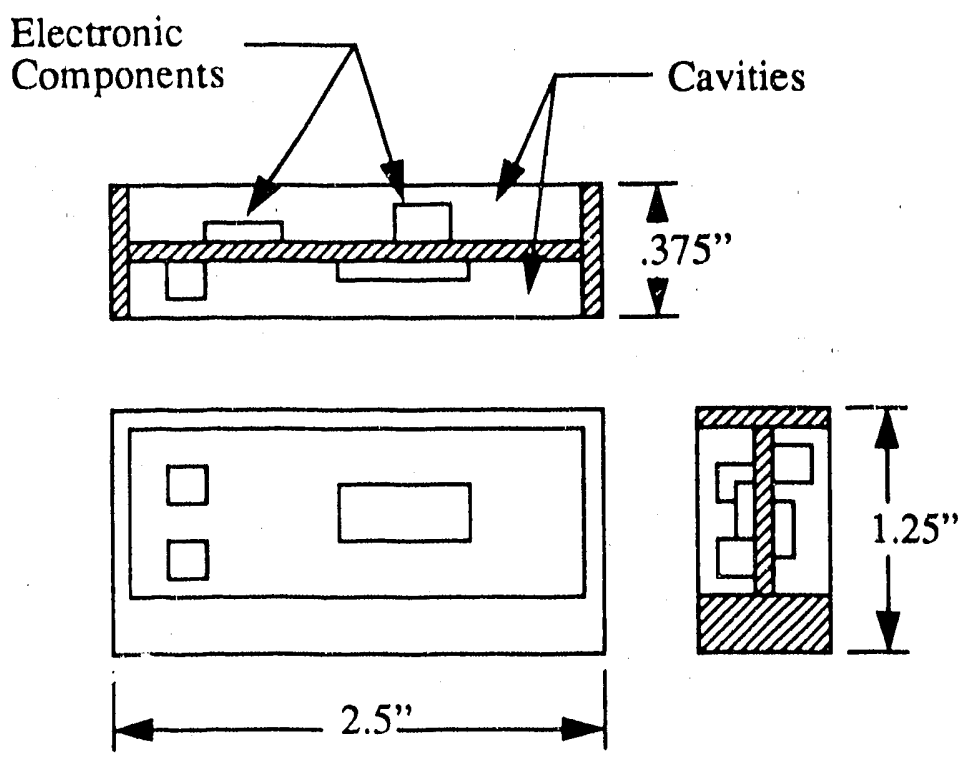

Note: Size of electronic components has been exaggerated.

FIGURE 1.

Radar Electronic Module Design

Phase-change materials (PCM's) have just recently been considered for temperature control of microelectronics $[1,2]$ and, since the late 1960 's, for thermal control in airborne electronic subsystems [3,4]. However, much research into heat transfer through a material undergoing a fusion phase change has been conducted since the late 1950's [5]. (All references to a phase-change material in this paper refer to a material that undergoes a solidliquid phase change.) Most early work was concerned with frozen food storage [6] and metal solidification $[7-9,14]$.

Most early analysis neglected convective effects in the melted region of the PCM. Heat transfer was thought to be mainly driven by conduction through the material $[5,6]$. The metallurgical industry first looked at convection in metal solidification. They were concemed with how the metals were solidifying. It was through these investigations that the irnportance of including convection in the analysis of heat transfer in a PCM first came to light $[7-9,14]$. It was found that although conduction was dominant at the onset and in early stages of melting, convection heat transfer needed to be considered for longer melt periods.

Much analytical and experimental determination of the heat transfer through a PCM was done throughout the 1970's [9-22] and 1980's [22-38]. Some considered conduction only $[11-13,15-17,22,25,26,30]$, and some included convective effects $[14,18-21,23$, $24,27-29,31-38]$. In considering conduction only, just the energy equation must be solved. For convection, the continuity and momentum equations must also be satisfied. In the momentum equations, the Boussinesq model which relates the density variation in the 
fluid to the temperature difference and considers density variation only as it contributes to buoyancy, is utilized $[18,23,24,27-29,31-36]$. Then either a strong $[10,13,18,23,24$, $27-29,31]$ or weak $[11,12,15-17,22,25,26,30,32-27]$ numerical formulation is used to solve the equations.

\begin{tabular}{|c|c|c|c|}
\hline \multicolumn{4}{|c|}{ NOMENCLATURE } \\
\hline a & height of enclosure & $Q_{\text {in }}$ & heat input \\
\hline A & Area & $\mathrm{R}$ & thermal resistance for conduction \\
\hline$b$ & width of enclosure & $\mathrm{R}_{\text {tot }}$ & total thermal resistance \\
\hline c & specific heat & $\mathrm{Ra}$ & Rayleigh number (based on \\
\hline $\mathrm{E}, \mathrm{e}$ & internal energy & & height) $\left[\operatorname{Prg} \beta \Delta \mathrm{Ta}^{3} / \mathrm{N}^{2}\right]$ \\
\hline $\mathrm{f}$ & aspect ratio $(a / b)$ & Ste & Stefan number $[c \Delta T / L]$ \\
\hline \multirow[t]{2}{*}{ Fo } & dimensionless time $\left[\alpha t / \mathrm{a}^{2}\right]$ & $\mathrm{t}$ & time \\
\hline & (Fourier number) & $\Delta \mathrm{t}$ & time increment \\
\hline \multirow[t]{2}{*}{$\Delta \mathrm{Fo}$} & dimensionless time step & $\mathrm{T}$ & temperature \\
\hline & {$\left[\alpha \Delta t / a^{2}\right]$} & $\mathrm{T}_{\mathrm{i}}$ & initial temperature \\
\hline g & acceleration due to gravity & $\mathrm{T}_{\mathrm{m}}$ & melt temperature \\
\hline $\mathrm{h}$ & sensible enthalpy & $\mathrm{T}_{1}$ & temperature of liquid region \\
\hline \multirow[t]{2}{*}{$\mathrm{h}_{\mathrm{m}}$} & sensible enthalpy of solid & $\mathrm{T}_{\mathrm{s}}$ & temperature of solid region \\
\hline & phase at $T_{m}$ & $\Delta \mathrm{T}$ & change in temperature \\
\hline \multirow[t]{2}{*}{$h^{*}$} & dimensionless sensible & $\mathrm{u}$ & velocity in $\mathrm{x}$-direction \\
\hline & enthalpy $\left[\left(h-h_{m}\right) / c\left(T_{m}-T_{i}\right)\right.$ & $v$ & velocity in $y$-direction \\
\hline $\mathrm{H}$ & total enthalpy $[\mathrm{h}+\Delta \mathrm{H}]$ & $\mathrm{V}$ & volume \\
\hline$\Delta \mathrm{H}, \mathrm{L}$ & latent heat of fusion & $x, y$ & coordinate directions \\
\hline$\Delta \mathrm{H}^{*}$ & $\begin{array}{l}\text { dimensionless latent heat } \\
{\left[\Delta \mathrm{H} / \mathrm{c}\left(\mathrm{T}_{\mathrm{m}}-\mathrm{T}_{\mathrm{i}}\right)\right]}\end{array}$ & $\Delta \mathrm{x}$ & $\begin{array}{l}\text { control volume width in } \\
x \text {-direction }\end{array}$ \\
\hline k & thermal conductivity & $\Delta y$ & control volume width in \\
\hline $\mathrm{m}$ & node number in $\mathrm{x}$-direction & & $y$-direction \\
\hline $\mathrm{n}$ & node number in $y$-direction & $\alpha$ & thermal diffusivity $[\mathrm{k} / \mathrm{\rho c}]$ \\
\hline $\mathbf{n}$ & unit vector normal to surface & $\beta$ & thermal expansion coefficient \\
\hline $\mathrm{p}$ & time step counter $[\mathrm{t}=\mathrm{p} / \mathrm{st}]$ & $\rho$ & density \\
\hline $\mathrm{P}$ & pressure & $\xi, \eta$ & dimensionless coordinates \\
\hline $\begin{array}{l}\text { Pr } \\
q^{\prime \prime}\end{array}$ & $\begin{array}{l}\text { Prandtl number of liquid }[v / \alpha] \\
\text { heat flux }\end{array}$ & $\Delta \xi, \Delta r$ & $\begin{array}{l}\text { dimensionless control volume } \\
\text { widths }\end{array}$ \\
\hline $\mathrm{q}^{*}$ & $\begin{array}{l}\text { dimensionless heat flux } \\
{\left[\mathrm{q}^{\prime \prime} \Delta \mathrm{x} / \mathrm{k}\left(\mathrm{T}_{\mathrm{m}}-\mathrm{T}_{\mathrm{i}}\right)\right]}\end{array}$ & $v$ & kinematic viscosity \\
\hline
\end{tabular}


For the strong formulation, after an initial period when conduction dominates the heat transfer, a marching solution employing a finite difference or finite element scheme is used to solve the system of equations consisting of the continuity, momentum and energy equations. This approach is valid assuming that the convective flow is in a quasi-steady state at each time step. Quasi-steady state in this context refers to a stationary melting front. For the parameters commonly used $\left(\operatorname{Pr} \approx 50, \mathrm{Ra} \approx 10^{8}, \mathrm{Ste} \approx 0.2\right)$, the velocity of the melting front propagation is several orders of magnitude less than the fluid boundary layer velocities, which suggests that the convective flow is not strongly influenced by the movement of the melting front. Therefore a quasi-steady state assumption for the convection process can be made [29]. After a quasi-steady state solution is obtained, an energy balance is done at the solid-liquid interface to determine the interface displacement so that the convection equations can be solved at the next time step. The process is repeated until the PCM is totally melted. To perform the energy balance, a deformed grid which follows the shape of the melting front must be used at the interface, which complicates the numerical formulation. The numerical procedure for the strong formulation is covered in detail in $[10,39]$.

For the weak formulation, enthalpy reformulation of the energy equation is used, which greatly simplifies the numerical scheme by ignoring the shape and exact location of the phase-change melting front $[22,25,32]$. As stated previously, the advantage of the weak formulation is that it is not necessary to explicitly describe the solution at any singularity; i.e. the melting front, and if an analytical solution exists, it will also be a weak solution [16]. This allows the problem to be solved with a fixed grid approach using a finite difference scheme to solve the entire system of equations simultaneously, thus simplifying the numerical calculations in a multi-dimensional analysis. Once the solution is obtained, the location of the melt front is known to an accuracy of the nodal spacing. Since the exact location of the melting front is not a concern in the heat transfer analysis presented in this paper, the enthalpy form of the energy equation was chosen as the best method of solution.

For electronic thermal control through the use of a PCM, normal paraffins ( $n$-paraffins) seem to be the best choice of material. In 1966, Northrop Corporation researched fusible materials to be used for temperature control systems for N.A.S.A. [3]. They found four $n$-paraffins that would be most suitable for this type of application; $n$-tetradecane $\left(\mathrm{C}_{14} \mathrm{H}_{30}\right)$, n-hexadecane $\left(\mathrm{C}_{16} \mathrm{H}_{34}\right)$, n-octadecane $\left(\mathrm{C}_{18} \mathrm{H}_{38}\right)$, and n-eicosane $\left(\mathrm{C}_{20} \mathrm{H}_{42}\right)$. They are inert and noncorrosive with very predictable thermophysical properties, have a high heat of fusion, and it should be relatively simple to incorporate them into the module package design. All properties of these four materials are very similar except for the melting temperature which is different in each case. A specific $n$-paraffin, $n$-octadecane, has been studied in most previous experiments $[20,29,31]$ and has a melt temperature of $28^{\circ} \mathrm{C}$. It is widely used for thermal energy storage. Another $n$-paraffin, $n$-eicosane has a melt temperature of $37^{\circ} \mathrm{C}$ and will be considered, along with $n$-octadecane, in the application section of this paper. Due to the sharp melting poinrs, all phase change will be considered isothermal. 


\section{THE GOVERNING EQUATIONS}

The governing equations to be solved in a rectangular region undergoing a phase change are:

For the liquid region

$$
\begin{array}{cr}
\frac{\partial u}{\partial x}+\frac{\partial v}{\partial y}=0 & \text { continuity } \\
\frac{\partial u}{\partial t}+u \frac{\partial u}{\partial x}+v \frac{\partial u}{\partial y}=-\frac{1}{\rho} \frac{\partial P}{\partial x}+v \nabla^{2} u & \text { x-momentum } \\
\frac{\partial v}{\partial t}+u \frac{\partial v}{\partial x}+v \frac{\partial v}{\partial y}=-\frac{1}{\rho} \frac{\partial P}{\partial y}+g \beta\left(T-T_{m}\right)+v \nabla^{2} v & \text { y-momentum }
\end{array}
$$

For the liquid and solid region

$$
\frac{\partial h}{\partial t}+\frac{\partial}{\partial t} \Delta H+u \frac{\partial h}{\partial x}+v \frac{\partial h}{\partial y}=\alpha \nabla^{2} h
$$

energy

The above enthalpy form of the energy equation is derived from first principles in Appen$\operatorname{dix} \mathrm{A}$ and appears there as equation (10).

All the preceding equations must be satisfied when one is concerned not only with conduction, but convection heat transfer as well. However, it has been empirically shown that a certain amount of time must elapse before convection currents are established to dominate conduction heat transfer. Bénard, Gobin, and Martinez [29] determineu through experiments that the transition time, $t_{0}$, for the boundary layer regime to establish in the liquid region for the onset of convection is given by

$$
t_{0}=4.59\left(\frac{P r}{S t e} \cdot \frac{\rho_{s}}{\rho_{L}} \cdot R a^{-\frac{1}{2}}\right)
$$

Using the properties of $n$-octadecane and $n$-eicosane, and the above equation with an assumed $\Delta T$ used in the Rayleigh number, the transition time, to, pertaining to the application considered in this paper is approximately 35-40 seconds. (The assumed $\Delta T$ used in the equation was conservatively estimated at $70^{\circ} \mathrm{C}$. However, as is evident in the application section of this paper, actual $\Delta T$ 's are much less which would increase the transition time even more.) Since this is about twice as long as the 10-20 second operation time 
of the radar module to be studied, this paper will present a numerical procedure to solve two-dimensional conduction with phase change* based on the enthalpy form of the energy equation.

After nondimensionalizing, the enthalpy form of the energy equation without convective terms becomes

$$
\frac{\partial}{\partial F_{o}} h^{*}+\frac{\partial}{\partial F_{o}} \Delta H^{*}=(f)^{2} \frac{\partial^{2}}{\partial \xi^{2}} h^{*}+\frac{\partial^{2}}{\partial \eta^{2}} h^{*}
$$

This equation appears as equation (13) in Appendix A.

* The solution of heat conduction through a material undergoing a phase change is often referred to as a Stefan problem, after J. Stefan who did some of the earliest analytical work in this area in 1891 [41]. 


\section{THE NUMERICAL PROCEDURE}

\section{The Numerical Algorithm}

Many numerical schemes for the solution of phase-change problems have been developed and written about in recent years $[10-13,15,16,22,24,30,33]$. Since the module geometry is rectangular and different geometries are not considered, a finite-difference approach was chosen over finite-element for simplicity. A "control volume" finite-difference formulation as outlined by Patankar $[10,39]$ was chosen for the numerical solution. Patankar refers to the nodal area or mesh element as a control volume.

This control volume approach uses central-difference approximations to the spatial derivatives and backward-difference approximations to the time derivatives. The dimensionless form of the energy equation was discretized in this manner (See Appendix B) and a set of equations for all interior and boundary nodes was developed. This set of implicit finite-difference equations is then solved in a FORTRAN program using the Gauss-Seidel iteration method.

To handle the latent heat sink term in the discretized equations, the method outlined by Voller $[32,33]$ is incorporated into the numerical code and is as follows (Also see Figure 2 which is a flowchart of the method). Recall the enthalpy form of the energy equation;

$$
\frac{\partial h}{\partial t}+\frac{\partial}{\partial t} \Delta H+u \frac{\partial h}{\partial x}+v \frac{\partial h}{\partial y}=\alpha \nabla^{2} h
$$

where $h=c T$ and the latent heat sink term for isothermal melting in a control volume is

$$
\Delta H_{C V}=F(T)=\left\{\begin{array}{cc}
L, & \left(T>T_{m}\right) \\
0<F(T)<L, & \left(T=T_{m}\right) \\
0, & \left(T<T_{m}\right)
\end{array} .\right.
$$

At the start of the algorithm, over one time step, the nodal latent heats take on the value of the previous time step (see step 1 in Figure 2). For each Gauss-Seidel iteration (see step 2), the nodal equations for the sensible heat are solved. After solving, each node's sensible enthalpy is added to that node's latent heat while the sensible enthalpy to initiate melting, $c T_{m}$, is subtracted (see step 3 ), i.e.,

$$
\left(\Delta H_{m, n}\right)_{i+1}=\left(\Delta H_{m, n}\right)_{i}+\left(h_{m, n}\right)_{i}-c T_{m} .
$$

A control volume is in the solid phase if $\left(h_{m, n}\right)_{i}<c T_{m}$ and $\left(\Delta H_{m, n}\right)_{i}=0$, and is in the liquid phase if $\left(h_{m, n}\right)_{i}>c T_{m}$ and $\left(\Delta H_{m, n}\right)_{i}=L$. Hence the following corrections (see step 5) are made prior to the next iteration. If $\left(\Delta H_{m, n}\right)_{i+1}<0$, set $\left(\Delta H_{m, n}\right)_{i+1}=0$, and if $\left(\Delta H_{m, n}\right)_{i+1}>L$, set $\left(\Delta H_{m, n}\right)_{i+1}=L$. If a control volume is changing phase, $\Delta H$ for that node remains as determined by the above equation. This is continued until convergence (see step 4). Convergence is achieved when $\left(h_{m, n}\right)_{i+1}^{p+1}-\left(h_{m, n}\right)_{i}^{p+1}$ is less than a 
specified number. Upon convergence of the Gauss-Seidel iteration process, over one time step, the nodal sensible enthalpies for those control volumes undergoing a phase change will be equal to $c T_{m}$ with the latent heat in the range, $0<\Delta H<L$.

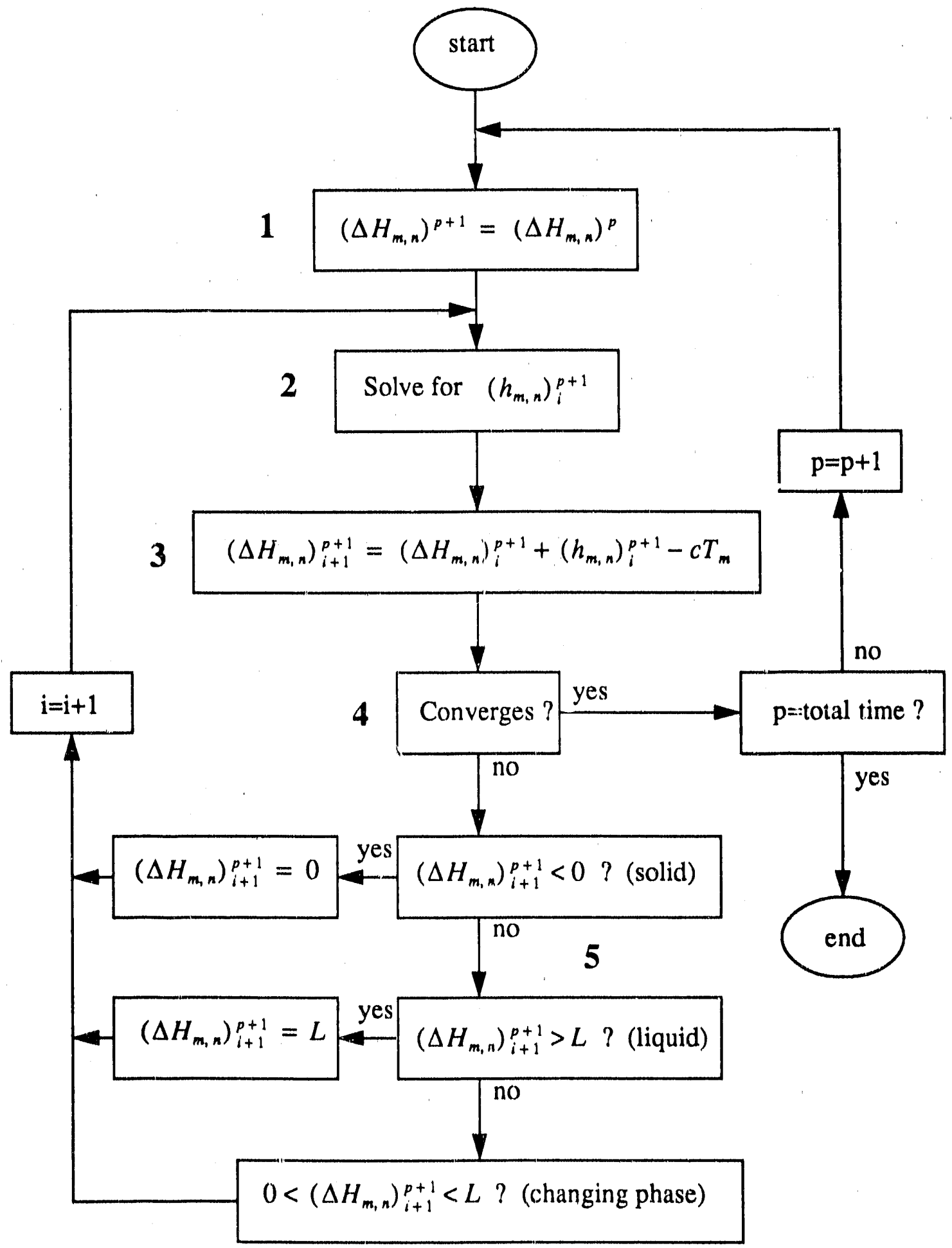

FIGURE 2.

Flowchart illustrating numerical updating of latent heat sink term. 


\section{Algorithm Verification}

In Voller's paper [33], solution of his algorithm for conduction only phase change is compared to the analytical conduction heat transfer solution of one-dimensional solidification in a semi-infinite region. Thus, to verify the melting algorithm, a FORTRAN program was written to solve the problem shown in Figure 3 (A listing of this program, titled heatcode2.f, is included in Appendix D). This problem is identical to the problem in Voller's paper except that this is a melting problem whereas his was a solidification problem.

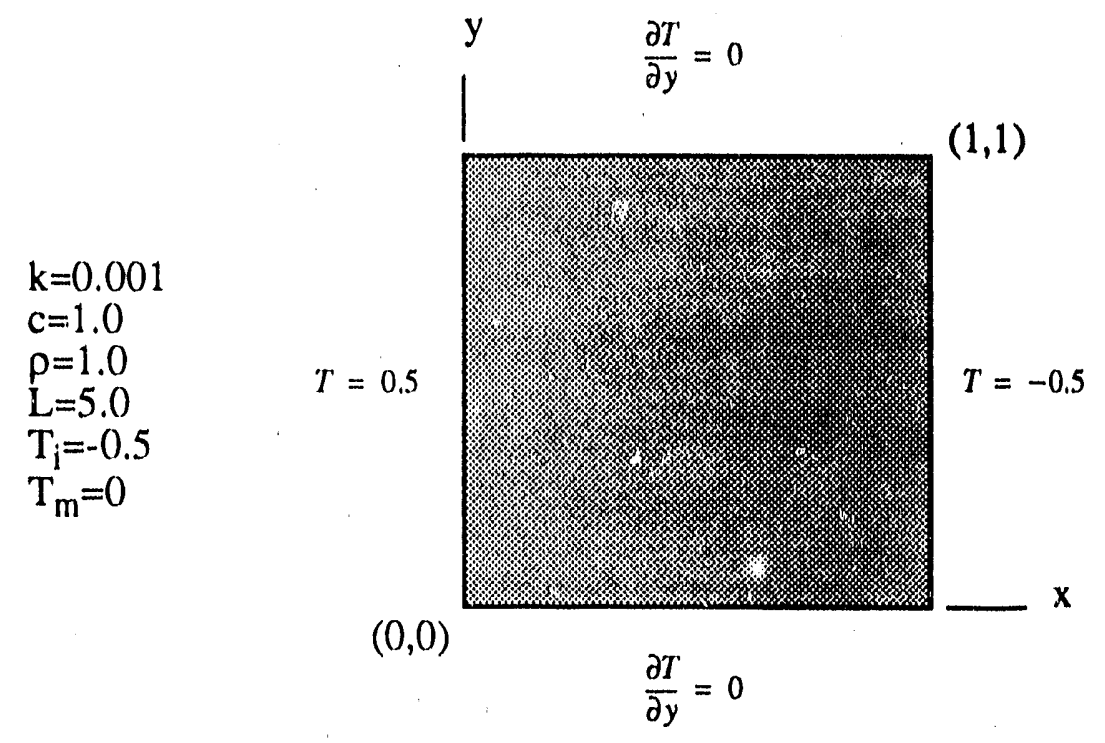

FIGURE 3.

Algorithm Verification Problem

Figure 4 shows a comparison, at $t=500$ seconds, of the numerical code results of the verification problem illustrated in Figure 3 and the analytical solution of one-dimensional melting in a semi-infinite region, using the same properties and boundary conditions as specified in Figure 3 except for $x=1$. The analytical solution was obtained by following the procedure outlined in Özisik [41] and is identical to the solidification problem except for a sign change. Assuming that the liquid and solid material properties are equivalent, the analytical solution yields the following equations for temperature in the liquid and solid phases;

$$
\frac{T_{1}(x, t)-T_{x=0}}{T_{m}-T_{x=0}}=\frac{\operatorname{erf}\left[x /\left(2(\alpha t)^{\frac{1}{2}}\right)\right]}{\operatorname{erf}(\lambda)}
$$




$$
\frac{T_{*}(x, t)-T_{i}}{T_{m}-T_{i}}=\frac{\operatorname{erfc}\left[x /\left(2(\alpha t)^{\frac{1}{2}}\right)\right]}{\operatorname{erfc}(\lambda)}
$$

solid region

where $\lambda$ is determined from

$$
-\left(\frac{T_{m}-T_{i}}{T_{m}-T_{x=0}} \cdot \frac{e^{-\lambda^{2}}}{\operatorname{erfc}(\lambda)}\right)-\frac{e^{-\lambda^{2}}}{\operatorname{erf}(\lambda)}=\frac{\lambda L \sqrt{\pi}}{c\left(T_{m}-T_{x=0}\right)} .
$$

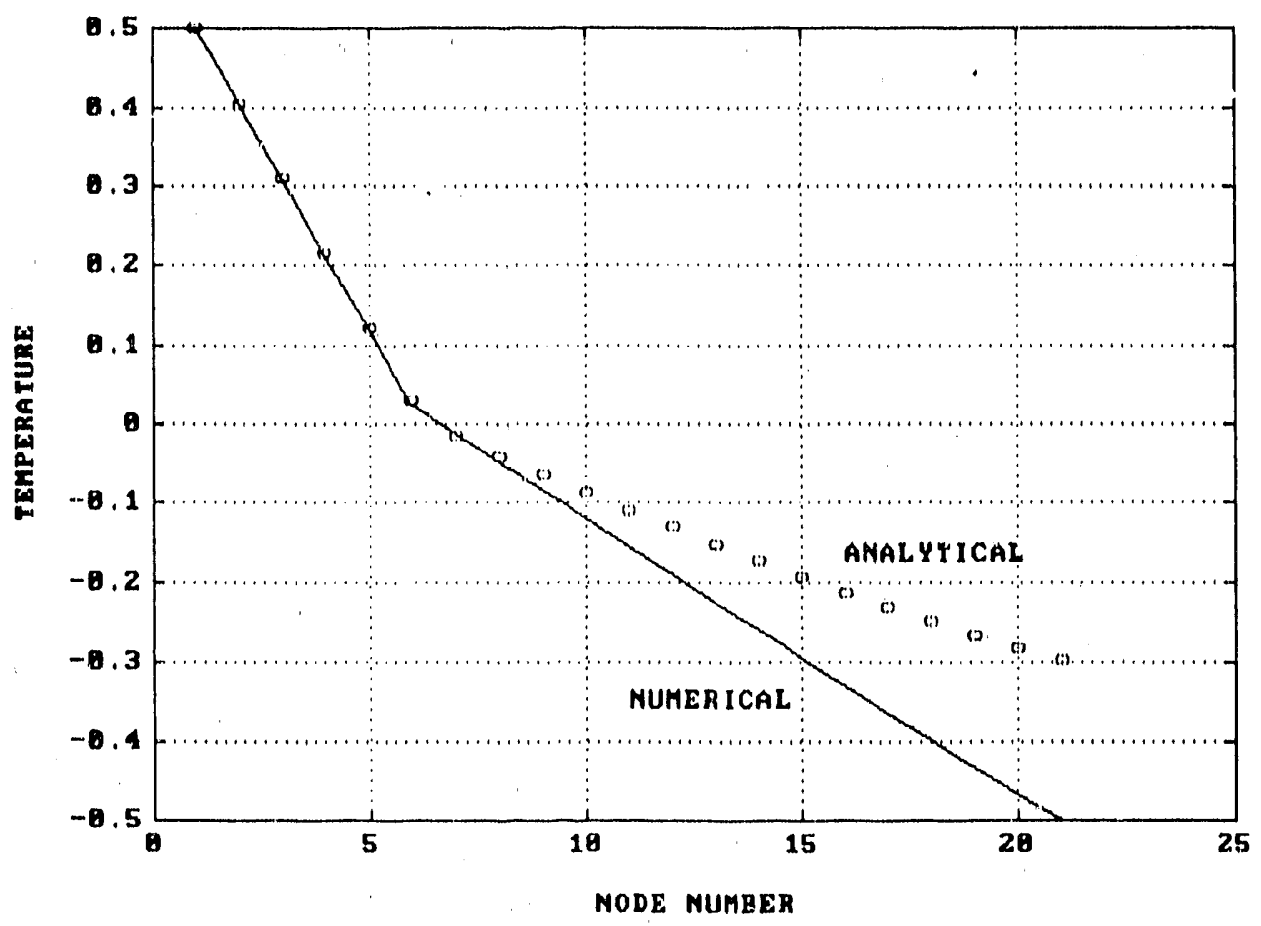

FIGURE 4.

Verification Problem Temperature Profile at $t=500 \mathrm{~s}$ 
For the numerical run plotted in Figure 4, there were 21 nodal points in the $x$-direction and the time step size was 1 second. The number of nodal points didn't affect the solution much; however this time step produced a solution which agreed well with the analytical solution. There is good agreement to the analytical solution in the liquid region, however, there is some divergence in the solid region due to the boundary condition at $x=1$. This is due to a finite region $(0 \leq x \leq 1)$ being approximated by a serni-infinite region $(0 \leq x \leq \infty)$. If the plot of the analytical solution was carried out farther in the $\mathrm{x}$-direction, it would asymptotically approach -0.5 as $x \rightarrow \infty$. These results correspond well to Voller's results [33]. It was deternined from these results that the numerical procedure and computer algorithm are fairly accurate in producing good results.

It shoulu be noted, however, that the program is very sensitive to time step size, spatial nodal spacing, convergence criteria, and even the material properties. All of these parameters are interrelated and when one or more is altered, the others must be modified until a satisfactory solution is obtained. For example, when this problem was run with a time step larger than 1 second. the solution obtained in the liquid region did not match the analytical solution quite as nicely. The slope of the temperature profile in the liquid region as shown in Figure 4 tended to become less steep as the time step size increased, thus diverging from the analytical solution. The time increment proved to be the most critical parameter. For some time increment sizes, the solution never achieved convergence at the start of the program while, for other time increment sizes, convergence was achieved after only one iteration. Variations in the other parameters, such as node spacing and convergence criteria, changed the solution slightly, but the temperature profiles varied by only about one degree per node. The nodal spacing can be any value, however the convergence criteria must be adjusted for each change in nodal spacing or time step. For the verification problem, the numerical solution matched the analytical solution best if convergence on the first time step was achieved between 50 and 80 iterations. Therefore, after finding an appropriate time increment and achieving convergence, the temperature profiles obtained can be considered accurate enough for the purpose of this paper. For this verification problem, agreement with the analytical solution gives an indication of the appropriate time step size. When the computer code is altered to handle different boundary conditions, as in the application problem which follows, additional checks are added to the code to assure accuracy. This is covered in detail in the following section. 


\section{APPLICATION: A RADAR MODULE:}

\section{The Model}

To compare the transient heat transfer in a si.all electronic module containing a PCM to one cooled by means of conduction alone, a sightly different modul seometry from the aforementioned radar electronic module is n clelled. In the model, a storage cavity containing a PCM is located directly behind the elsctronic components (Sec Figure 5). This rectangular cavity is the area for the two-dimensional heat transfer analysis. A spatially uniform heat flux, constant with time, is assumed at the left (electronic component) boundary, and the remainin, three boundaries are assumed adiabatic (See Figure 6). The boundary conditions shown in Figure 6 are deduced from the configuration of the modules shown in Figure 5 and simplified for purposes of numerical analysis. For the PCM model, since the objective is to remove the heat from the electionics quickly by absorbing the latent heat, the center web should be as thin as structurally feasible to minimize the thermal resistance between the electronic heat sources and the PCM. The PCM will initially $b_{c}$ in the solid phase with an air gap at the top of the enclosure to allow for expansion upon meliing. This air gap is assumed to be small enough to have little effect on the solution and will be ignored. To compare to a module without a PCM, the cavity is simply analyzed in the same fashion assuming it is solid aluminum.

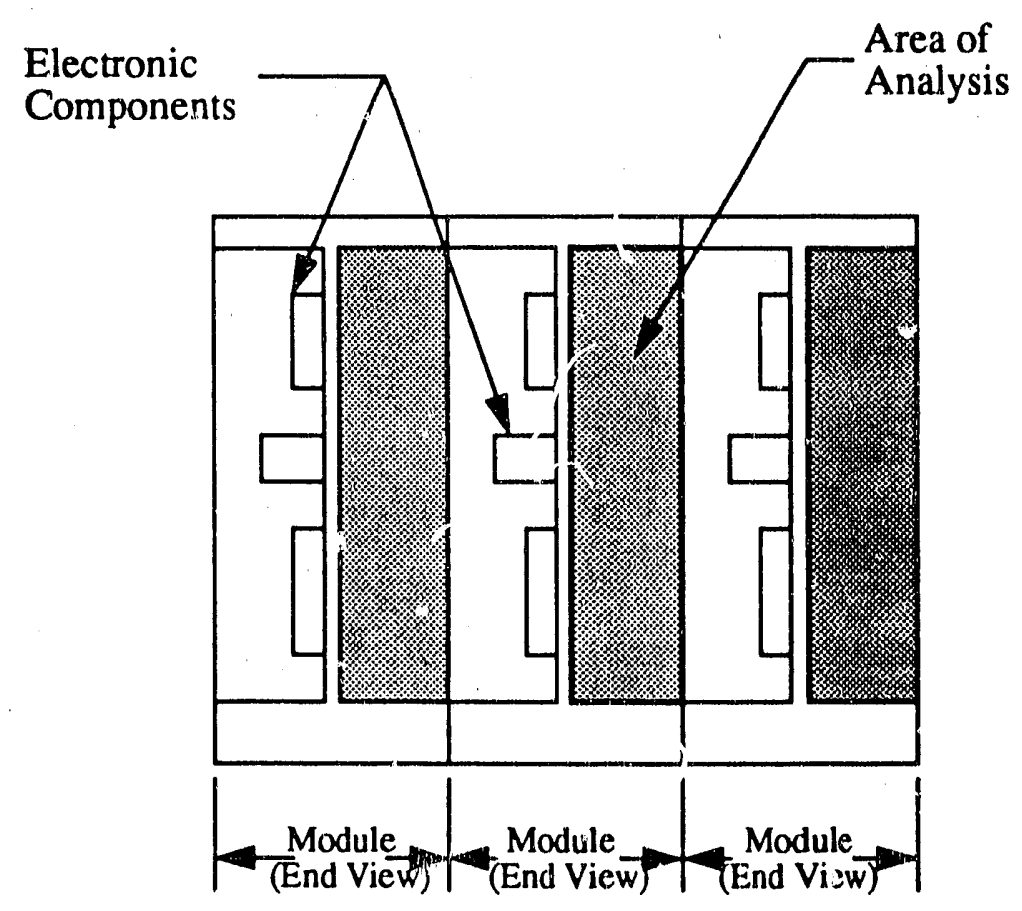

FIGURE 5.

PCM Model Module Configuration 


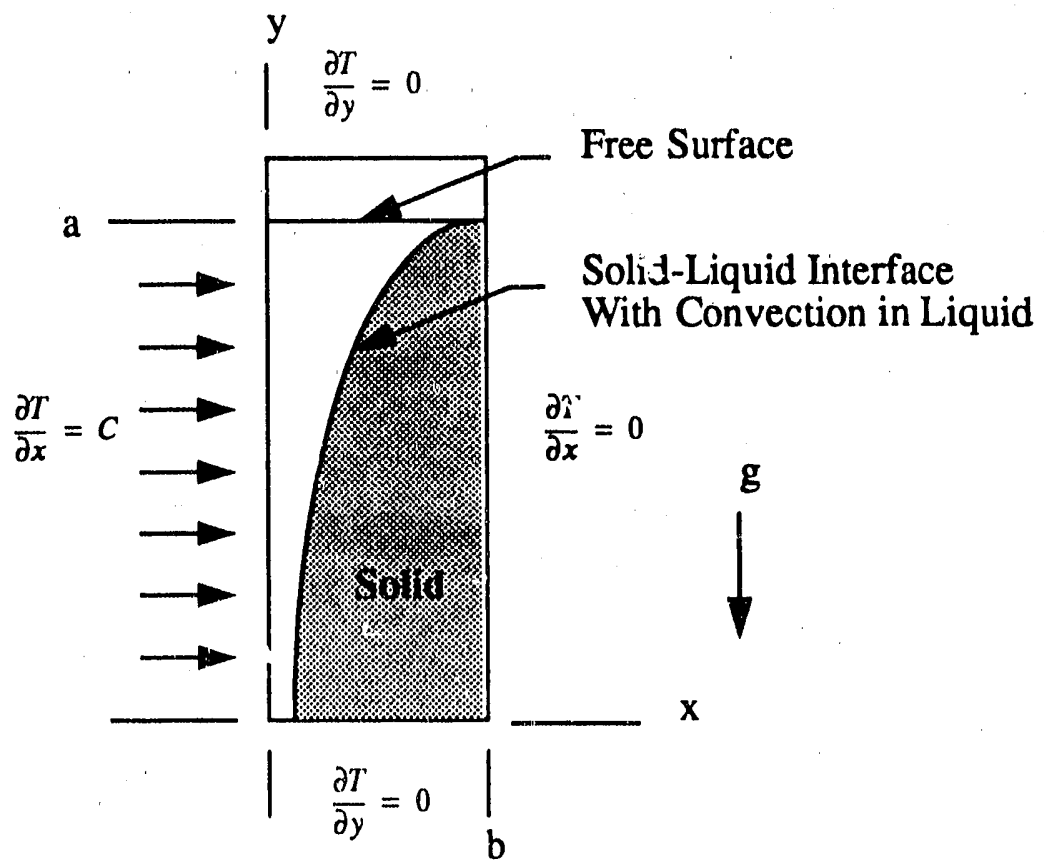

FIGURE 6.

PCM Model Geometry

\section{The Numerical Solution}

The IORTRAN program written for the verification problem was modified to handle the boundary conditions of the application problem and to accept either dimensional or dimensionless input and output ( $A$ listing of this program, titled heatcode.f is also included in Appendix D). To determine if the solution is approaching a true solution, a cumulative energy balance is calculated at each time step to compare with the known energy input to the system. Therefore, when the program is run at different time step sizes, spatial nodal spacings, and convergence criteria, this energy value also gives an indication of the accuracy of the solution in addition to comparison with engineering approximations of the temperature history.

Numerical solutions were obtained using the properties of $n$-octadecane and $n$-eicosane which are tabulated in Table 1 . Since the code was not written to handle varying material properties, an average value was used (see Table 1). The two paraffins were assumed to have the same properties, except for the melt temperature.

In addition to the material properties of the PCM, the heat flux along the left boundary and an initial temperature are input to the code. For the radar module problem, the heat flux associated with a $15 \mathrm{~W}$ module is $15000 \mathrm{~W} / \mathrm{m}^{2}$. This flux and twice the amount, $30000 \mathrm{~W} / \mathrm{m}^{2}$, were run for comparison of results. The PCM was initially in the solid phase at $20^{\circ} \mathrm{C}$, assuming room temperature, and subjected to the flux. The cavity dimensions are $a=2.0 \mathrm{~cm}$ and $\mathrm{b}=0.5 \mathrm{~cm}$ with a unit depth of $1.0 \mathrm{~m}$. For all numerical solutions presented, there were 20 nodal points in the $x$-direction and 10 nodal points in the $y$-direction. A time 
step size of 0.0005 seconds along with various convergence criteria was used in all solutions. The various convergence criteria were chosen by studying the energy balance at each time step, which will be explained further in the next section.

\begin{tabular}{|c|c|c|}
\hline Material Property & $\begin{array}{l}\text { Actual } \\
\text { Value }\end{array}$ & $\begin{array}{l}\text { Average } \\
\text { Value Used }\end{array}$ \\
\hline $\begin{array}{l}\text { Fusion Temperature }\left({ }^{\circ} \mathrm{C}\right) \\
n \text {-octadecane } \\
n \text {-eicosane }\end{array}$ & $\begin{array}{c}28.05 \\
37\end{array}$ & $\begin{array}{l}28 \\
37\end{array}$ \\
\hline Latent Heat $\left(\mathrm{J} \mathrm{kg}^{-1}\right)$ & 241000 & 241000 \\
\hline $\begin{array}{l}\text { Thermal Conductivity } \\
\left(\mathrm{W} \mathrm{m}^{-1}{ }^{\circ} \mathrm{C}^{-1}\right) \\
\text { solid }\end{array}$ & 0.390 & \\
\hline $\begin{array}{l}\text { liquid } \\
\text { Aluminum Enhanced }\end{array}$ & 0.157 & $\begin{array}{l}0.230 \\
17.91\end{array}$ \\
\hline $\begin{array}{l}\text { Specific Heat }\left(\mathrm{J} \mathrm{kg}^{-1}{ }^{\circ} \mathrm{C}^{-1}\right) \\
\text { solid } \\
\text { liquid }\end{array}$ & $\begin{array}{l}1900 \\
2200\end{array}$ & 2050 \\
\hline $\begin{array}{l}\text { Density }\left(\mathrm{kg} \mathrm{m}^{-3}\right) \\
\text { solid } \\
\text { liquid @ } 30^{\circ} \mathrm{C}\end{array}$ & $\begin{array}{l}815 \\
775\end{array}$ & 790 \\
\hline $\begin{array}{l}\text { Kinematic Viscosity } \\
\left(\mathrm{m}^{2} \mathrm{~s}^{-1}\right) \\
@ 40^{\circ} \mathrm{C} \\
@ 30^{\circ} \mathrm{C}\end{array}$ & $\begin{array}{l}4 \times 10^{-6} \\
5 \times 10^{-6}\end{array}$ & $4.5 \times 10^{-6}$ \\
\hline
\end{tabular}

TABBLE 1.

Material Properties of $n$-Octadecane and $n$-Eicosane

Obtained from Bentilla, Sterrett and Karre [3], and Bénard, Gobin and Zanoli [31]

\section{Results and Discussion}

The computer model was first used to predict the performance of a module with just an aluminum filled cavity, and the results are illustrated in Figure 7. Because of the boundary conditions, the heat transfer was primarily one-dimensional, therefore an arbitrary slice half way up the $y$-axis gives a good indication of the temnerature profile throughout the PCM at any time. All temperature profiles presented in this report use that midpoint temperature profile as representative of the system performance. Figure 7 shows that the maximum temperature occurs at $\mathrm{x}=0$ and that the temperature profile across the aluminum varies by only $1^{\circ} \mathrm{C}$ which suggests that a lumped parameter model would be an appropriate calculation to check the validity of the numerical results. 
A simple energy balance on the cavity yields the equation: $Q_{i n}=\rho V c \Delta T$. With an initial temperature of $20^{\circ} \mathrm{C}$ and a heat flux of $15000 \mathrm{~W} / \mathrm{m}^{2}$, the final temperatures for 10 seconds and 20 seconds of operation respectively are $32{ }^{\circ} \mathrm{C}$ and $44^{\circ} \mathrm{C}$. Comparing the results of the two methods shows good agreement of the predicted wall temperatures.

Note that the average temperatures from Figure 7 are not exactly the same as the lumped parameter results. It was found that comparing the cumulative internal energy change to the known cumulative energy input was a valuable aid in determining the appropriate value for the convergence criteria. For example, the cumulative energy input for a period of 10 seconds in Figure 7 with a heat flux of $15000 \mathrm{~W} / \mathrm{m}^{2}$ was $3000 \mathrm{~J} / \mathrm{m}$ and the cumulative energy absorbed was only $2818 \mathrm{~J} / \mathrm{m}$ (a $6 \%$ error) which accounts for the slightly lower average temperature. Setting more stringent values for the convergence criteria resulted in unacceptably long computer runs, and, in the extreme, failure to converge.

Figure 8 shows temperature profiles, for both heat fluxes, at $t=10$ seconds with $n$-eicosane as the PCM. As node 0 corresponds to $\mathrm{x}=0$, it is evident that the temperature right behind the electronics is much higher in this case than with the aluminum heat sink. It is also evident that doubling the heat flux more than doubles the temperature rise at the left boundary. The sharp temperature rise from node 5 to node 0 is in the liquid region and is due to the poor thermal conductivity of the paraffin. Clearly, to decrease this sharp temperature rise in the liquid region, the thermal conductivity of the PCM must be improved. Duffy [4] proposed putting an aluminum honeycomb structure throughout the PCM cavity to increase thermal conductivity into the PCM and empirically showed an improvement. In order to estimate the performance of such a honeycomb structure, a composite thermal conductivity has been used to reduce an essentially three-dimensional problem to a twodimensional problem. In Appendix C, a conservative estimate of increased thermal conductivity is derived and the result is shown in Table 1 for an aluminum enhanced PCM.

Numerical solutions obtained for aluminum enhanced $n$-eicosane with a heat flux of $15000 \mathrm{~W} / \mathrm{m}^{2}$ are shown in Figure 9 . Note that the temperature rise in the liquid region is much less, due to the improved thermal conductivity. The solution indicates a temperature of $37^{\circ} \mathrm{C}$ after 10 seconds and only $37.7^{\circ} \mathrm{C}$ after 20 seconds on the left boundary. This solution for 20 seconds of operation shows improvement over the aluminum heat sink (see Figure 7 for $\mathrm{t}=20 \mathrm{~s}$ ). Recall that $n$-eicosane has a melt temperature of $37^{\circ} \mathrm{C}$. Since $n$-octadecane has a melt temperature of $28^{\circ} \mathrm{C}$, results with it as the PCM should show a substantial improvement.

Figures 10 and 11 show just that. Numerical solutions with aluminum enhance $n$-octadecane show improvement over an aluminum heat sink for both run times and for both heat fluxes. Comparing results in Figure 10 with the final temperatures obtained for the aluminum heat sink, illustrated in Figure 7, it is evident that improvement in cooling, evident through a lower temperature excursion, increases with longer operation times.

Since the density of the $n$-paraffins is $1 / 3$ to $1 / 4$ that of aluminum, the weight of the heat sink is considerably lighter. And since melting occurred in only about $1 / 4$ of the total cavity and little energy is stored in the solid, the PCM cavity could be designed considerably smaller than the aluminum heat sink, thus producing an even greater weight savings. 

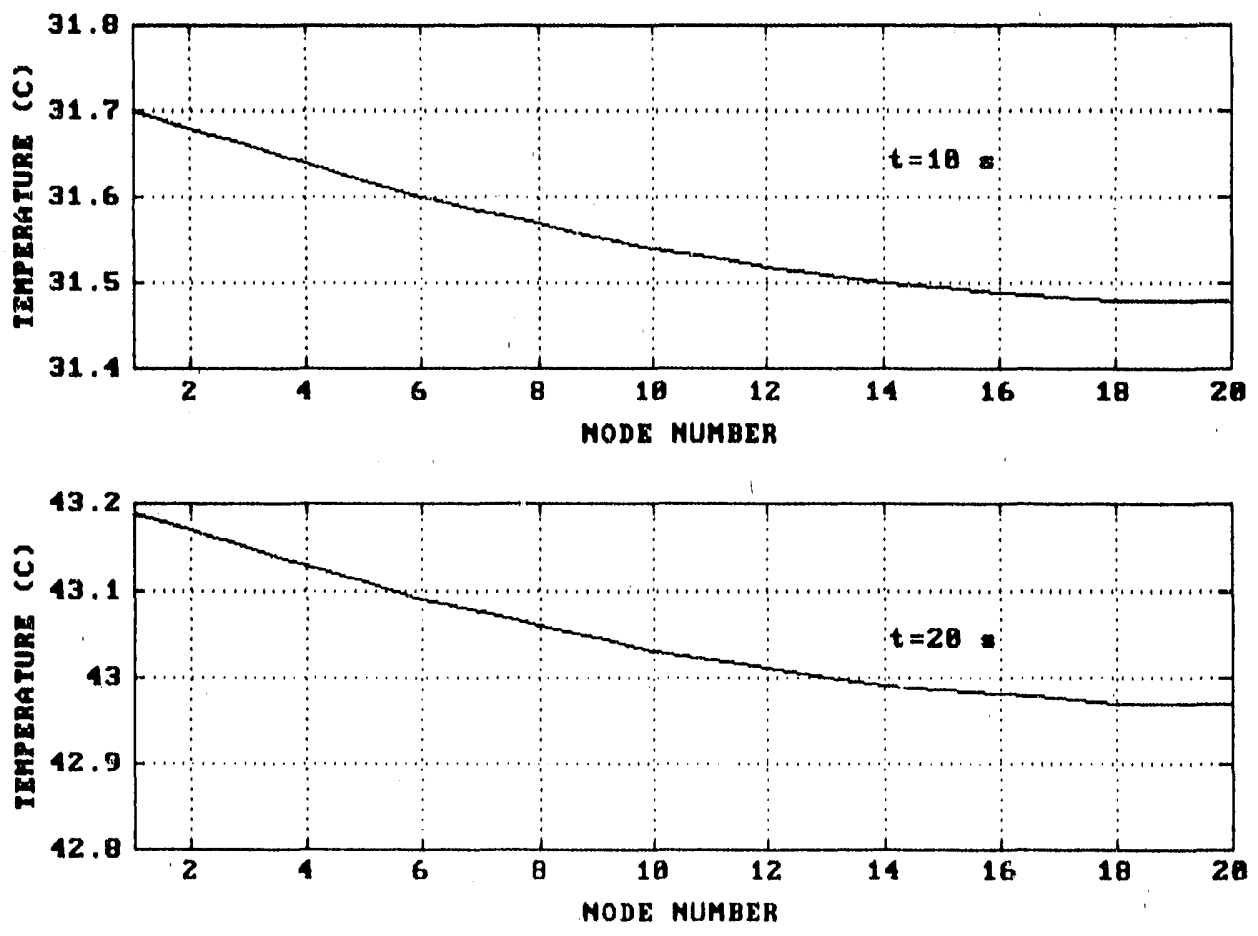

FIGURE 7.

Application Temperature Profiles, $q^{\prime \prime}=15000 \mathrm{~W} / \mathrm{m}^{2}$, Aluminum

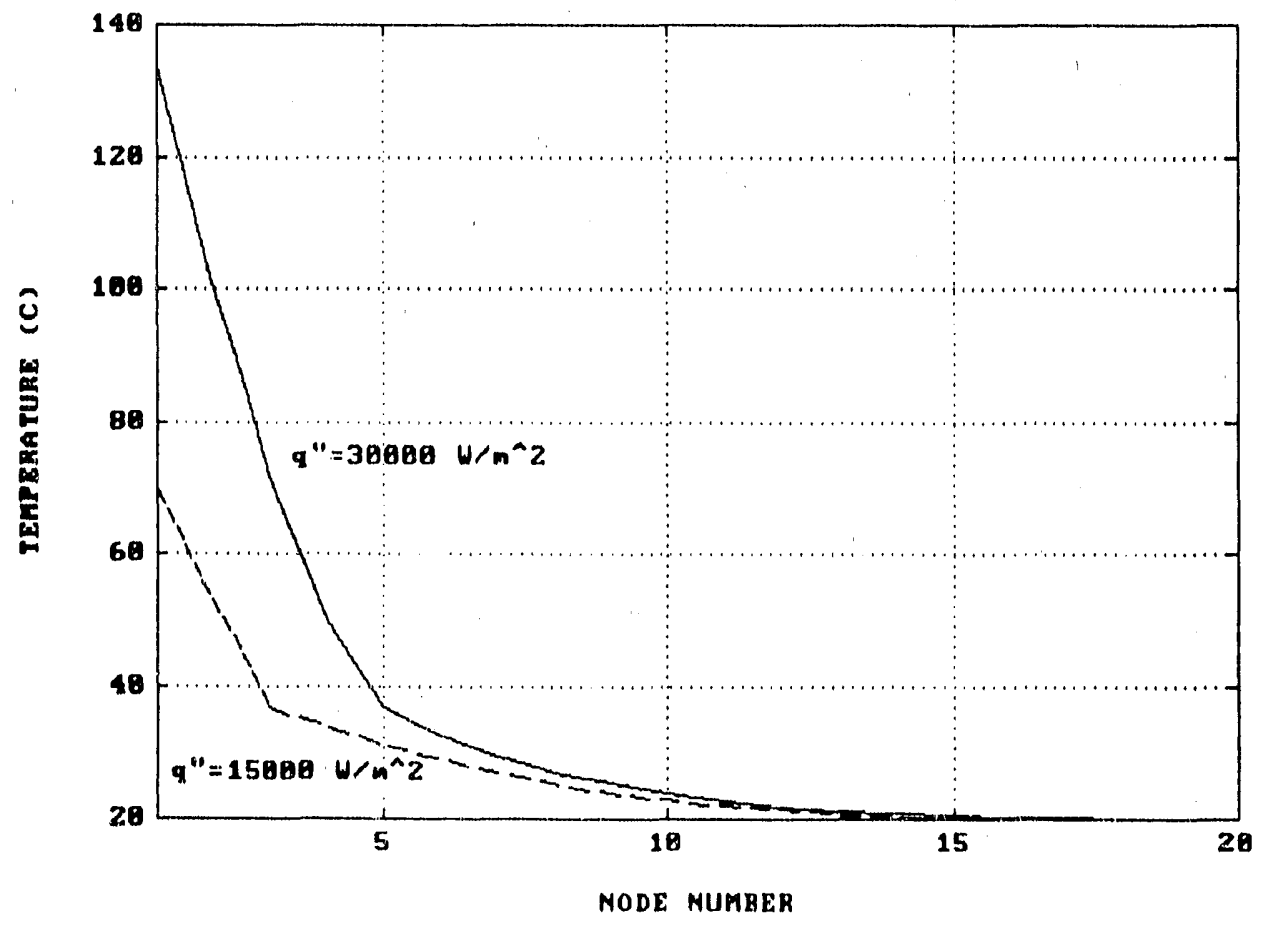

FIGURE 8.

Application Temperature Profiles at $\mathrm{t}=10 \mathrm{~s}, n$-Eicosane 


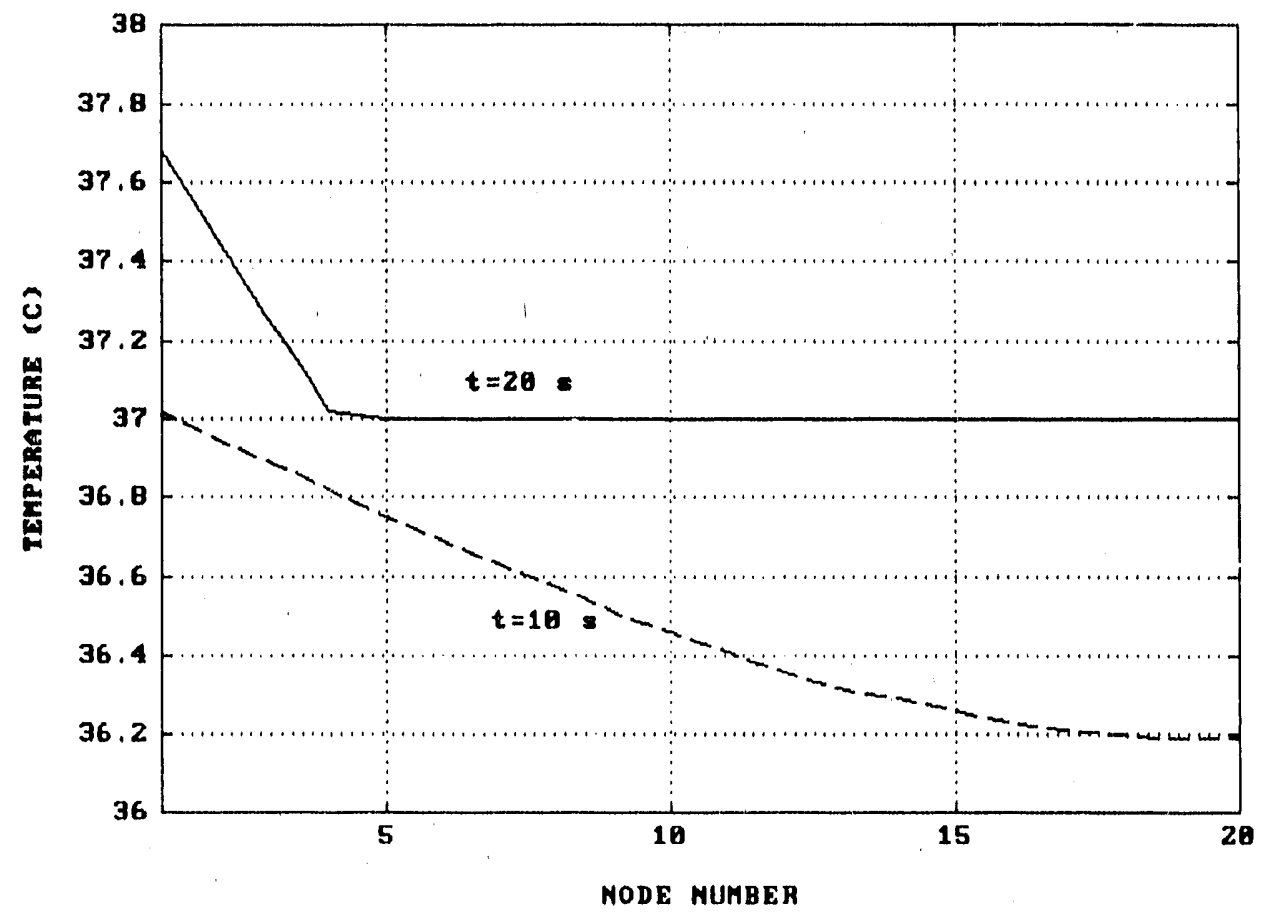

FIGURE 9.

Application Temperature Profiles, $\mathrm{q}^{\prime \prime}=15000 \mathrm{~W} / \mathrm{m}^{2}$, Aluminum Enhanced $n$-Eicosane

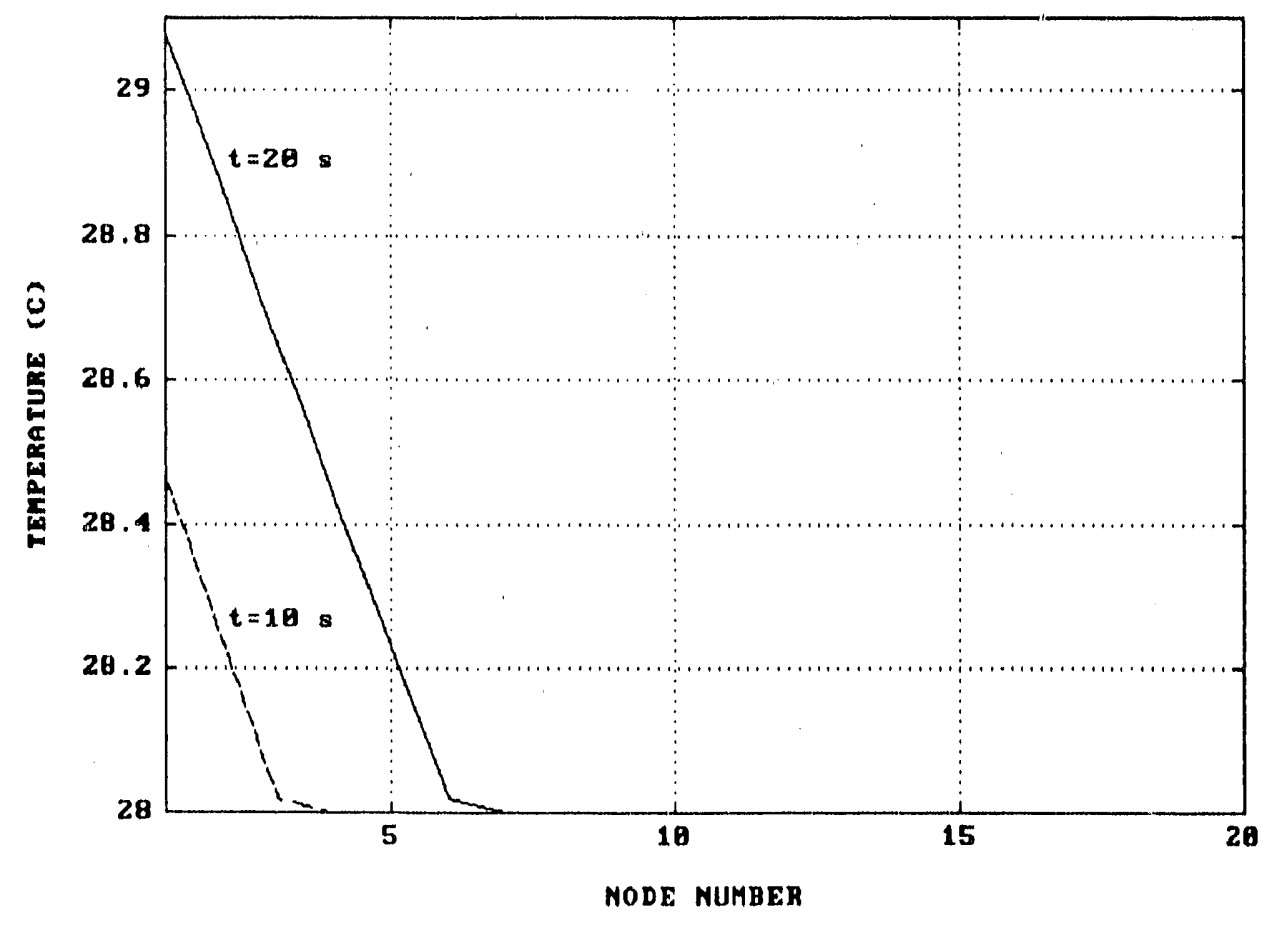

FIGURE 10.

Application Temperature Profiles, $\mathrm{q}^{\prime \prime}=15000 \mathrm{~W} / \mathrm{m}^{2}$, Aluminum Enhanced $n$-Octadecane 


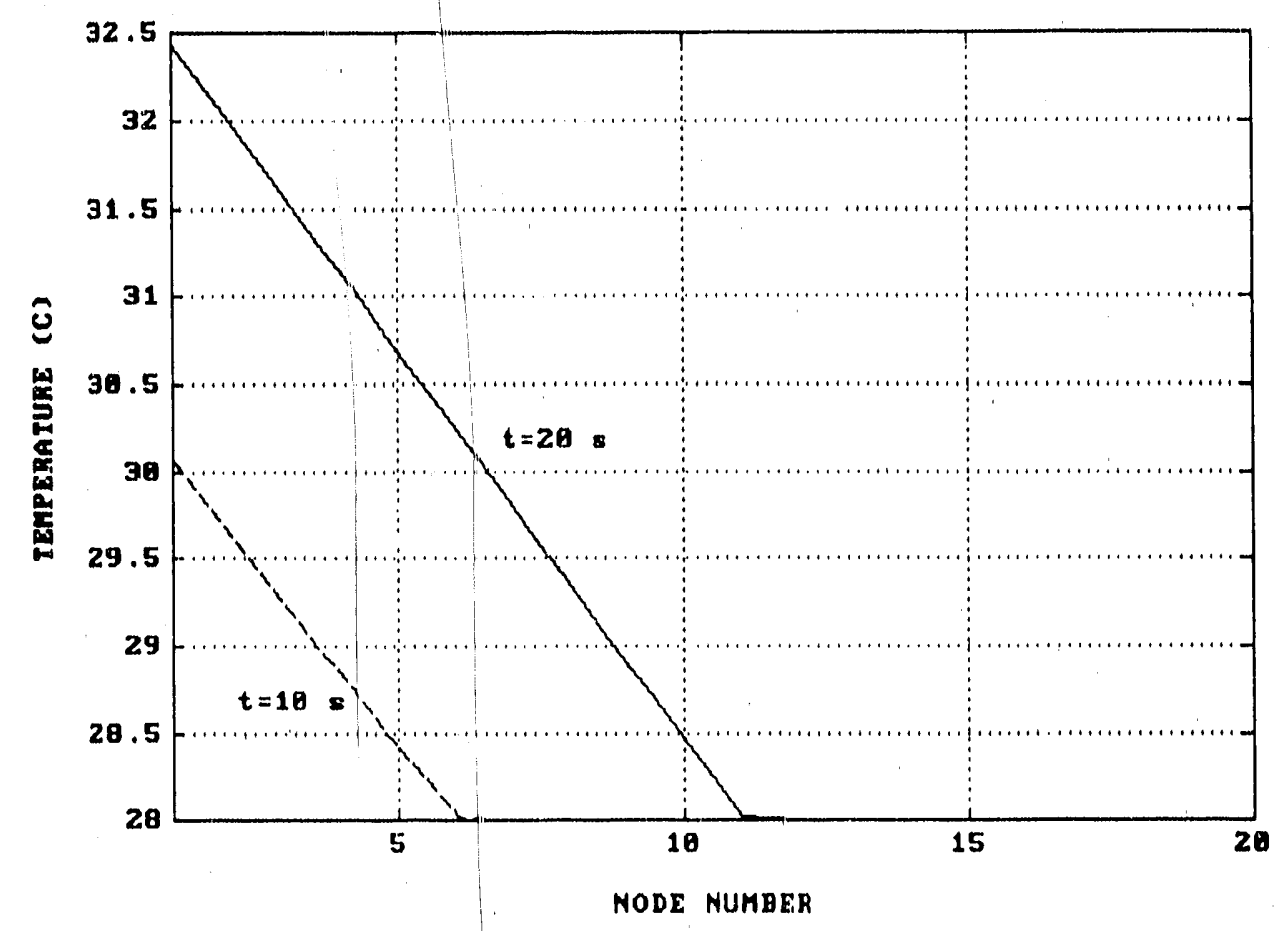

FIGURE 11.

Application Temperature Profiles, $\mathrm{q}^{\prime \prime}=30000 \mathrm{~W} / \mathrm{m}^{2}$, Aluminum Enhanced $n$-Octadecane

\begin{tabular}{|l|c|c|c|}
\hline \multicolumn{1}{|c|}{ Material } & $\begin{array}{c}\text { Max. Temp } \\
@ \mathrm{t}=10 \mathrm{~s}\end{array}$ & $\begin{array}{l}\text { Max. Temp. } \\
\text { @ } \mathrm{t}=20 \mathrm{~s}\end{array}$ & $\begin{array}{l}\text { Approx. } \\
\text { Weight }\end{array}$ \\
\hline Aluminum & $31.7^{\circ} \mathrm{C}$ & $43.2^{\circ} \mathrm{C}$ & $277 \mathrm{~g} / \mathrm{m}$ \\
$n$-Eicosane & $70.0^{\circ} \mathrm{C}$ & - & $79 \mathrm{~g} / \mathrm{m}$ \\
$\begin{array}{l}\text { Aluminum Enhanced } \\
n \text {-Eicosane }\end{array}$ & $37.0^{\circ} \mathrm{C}$ & $37.7^{\circ} \mathrm{C}$ & $99 \mathrm{~g} / \mathrm{m}$ \\
$\begin{array}{l}\text { Aluminum Enhanced } \\
\text { n-Octadecane }\end{array}$ & $28.5^{\circ} \mathrm{C}$ & $29.1^{\circ} \mathrm{C}$ & $99 \mathrm{~g} / \mathrm{m}$ \\
\hline
\end{tabular}

TABLE 2.

Comparison of Results

$\left(q^{\prime \prime}=15000 \mathrm{~W} / \mathrm{m}^{2}\right.$, cavity size equal in all cases $)$ 


\section{CONCLUSIONS}

It has been shown in this paper and summarized in Table 2 that, through the use of a PCM, the heat transfer in a small electronic radar module can be improved. After $20 \mathrm{sec}-$ onds of operation an alurninum heat sink weighing $277 \mathrm{~g}$ wciuld have a maximum temperature of $43.2^{\circ} \mathrm{C}$ while an aluminum enhanced $\mathrm{n}$-octadecane paraffin occupying the same volume and weighing only $99 \mathrm{~g}$ would have a maximum temperature of only $29.1^{\circ} \mathrm{C}$ and would have used only a third of its absorption capacity. The findings of this investigation could also be applied to other electronic subsystems as well. As electronic systems get smaller and dissipate more heat, unique cooling schemes such as PCM heat reservoirs should become more commonplace.

The enthalpy form of the energy equation has proved to be an efficient means of numerically analyzing the heat transfer in a material undergoing a phase change for the type of application considered in this report. Since this equation governs both the liquid and solid regions and knowledge of the exact location of the phase-change front is unnecessary, a fixed grid methodology may be employed, thus simplifying the numerical algorithm.

Results obtained through the numerical algorithm outlined in this paper should by no means be considered exact. The algorithm and especially the latent heat source term updating procedure have just recently been developed and have not been substantiated by experiments [32]. However, the numerical solutions, when checked with energy balances and against an existing analytical solution produce results with enough accuracy for most design purposes. The results indicate that further study, consideration, and experimental work in using PCM's in radar packages is warranted. The FORTP AN programs listed in the Appendix of this report should prove useful to anyone analyzing heat flow through a material changing phase.

In studying the heat transferring capabilities of a PCM, it has been shown that, alone, the $n$-paraffins have too low thermal conductivity to be useful. However, if the thermal conductivity can be improved through "loading" with a higher thermal conductivity material, or by using a honeycomb structure to disperse the heat more rapidly into the paraffin, these materials show great promise for cooling electronics that operate for short time intervals. The weight savings in using a paraffin for a heat sink over the typical metal he? sink is significant also. In airborne vehicles, such as the vehicle for which this radar module is designed, weight is an important issue. Designers are constantly looking for ways to lighten their airborne electronic packages, and using PCM's for thermal control offers just that.

More research, including experimental work, needs to be undertaken before PCM's become a common means of cooling electronic packages. Development of PCM's with higher thermal conductivity is needed and should be considered. In airborne vehicles and in space systems where other cooling inethods are impractical or impossible, thermal management through the use of a phase-change material looks extremely promising. 


\section{REFERENCES}

1. Chebi, R., Rice, P. A., and Schwartz, J. A., "Heat Dissipation in Microelectronics Systems Using Phase Change Materials With Natural Convection," Chem. Eng. Comm., Vol. 69, pp. 1-12, 1988.

2. Witzman, S., Shitzer, A., and Zvirin, Y., "Simplified Calculation Procedure of a Latent Heat Reservoir for Stabilizing the Temperature of Electronic Devices," ASME Journal of Heat Transfer; Vol. 28, 1983, pp. 29-34.

3. Bentilla, E. W., Sterrett, K. F., and Karre, L. E., "Research and Development Study on Thermal Control By Use of Fusible Materials," Northrop Space Laboratories, Contract No. NAS 8-11163, NASA Document No. N66-26691, 1966.

4. Duffy, Victor, "Thermal Control Through Fusible Materials," Electronic Packaging and Production, July 1970, pp. 45-53.

5. Goodman, T. R., "The Heat-Balance Integral and Its Application to Problems Involving a Change of Phase," ASME Journal of Heat Transfer, Vol. 80, No. 2, pp. 335-342, 1958.

6. Baxter, D. C., "The Fusion Times of Slabs and Cylinders," ASME Journal of Heat Transfer, Vol. 84, pp. 317-326, 1962.

7. Cole, G. S., "Temperature Measurements and Fluid Flow Distributions Ahead of SolidLiquid Interfaces," Trans. Met. Soc. AIME, Vol. 239, pp. 1287-1295, 1967.

8. Szekely, J., and Chhabra, P. S., "The Effect of Natural Convection on the Shape and Movement of the Melt-Solid Interface in the Controlled Solidification of Lead," Met. Trans., Vol. 1, pp. 1195-1203, 1970.

9. Szekely, J., and Stanek, V., "Natural Convection Transients and Their Effects in Unidirectional Solidification," Met. Trans., Vol. 1, pp. 2243-2251, 1970.

10. Patankar, S. V., and Spalding, D. B., "A Calculation Procedure For Heat, Mass and Momantum Transfer in Three-dimensional Parabolic Flows," Int. Journal of Heat and Mass Transfer, Vol. 15, pp. 1787.1806, 1972.

11. Bonacina, C., Comini, G., Fasano, A., and Primicerio, M., "Numerical Solution of Phase-Change Problems," Int. Journal of Heat and Mass Transfer, Vol. 16, pp.1825$1832,1973$.

12. Meyer, G. H., "Multidimensional Stefan Problems," SIAM Journal of Numerical Analysis, Vol. 10, No. 3, pp. 522-538, 1973.

13. Comini, G., Del Guidice, S., Lewis, R. W., and Zienkiewicz, O. C., "Finite Element Solution of Non-linear Heat Conduction Problems with Special Reference to Phase Change," Int. Journal for Numerical Methods in Engr., Vol. 8, pp. 613-624, 1974. 
14. Chiesa, F. M., and Guthrie, R. I. L., "Natural Convective Heat Transfer Rates During the Solidification and Melting of Metals and Alloy Systems," ASME Journal of Heat Transfer, Vol. 96, pp. 377-384, 1974.

15. Atthey, D. R., "A Finite Difference Scheme for Melting Problems," Journal Inst. Maths. Applics., Vol. 13, pp. 353-366, 1974.

16. Atthey, D. R., "A Finite Difference Scheme for Melting Problems Based on the Method of Weak Solutions," in Moving Boundary Problems in Heat Flow and Diffusion (edited by J. R. Ockendon and W. R. Hodgkins), pp. 182-191, Oxford University Press, Oxford, 1975.

17. Shamsundar, N and Sparrow, E. M., "Analysis of Multidimensional Conduction Phase Change Via the Enthalpy Model," ASME Journal of Heat Transfer, Vol. 97, No. 3, pp. 333-340, 1975.

18. Sparrow, E. M., Patankar, S. V., and Ramadhyani, S., "Analysis of Melting in the Presence of Natural Convection in the Melt Region," ASME Journal of Heat Transfer, Vol. 99 , pp. 520-526, 1977.

19. Sparrow, E. M., Schmidt, R. R., and Ramsey, J. W., "Experiments on the Role of Natural Convection in the Melting of Solids," ASME Journal of Heat Transfer, Vol. 100, pp. 11-16, 1978.

20. Hale, N. W., Jr., and Viskanta, R., "Photographic Observation of the Solid-Liquid Interface Motion During Melting of a Solid Heated From an Isothermal Vertical Wall," Letters in Heat and Mass Transfer, Vol. 5, pp. 329-337, 1978.

21. Marshall, R. H., "Natural Convection effects in Rectangular Enclosures Containing a Phase Change Material," In Thermal Storage and Heat Transfer in Solar Energy Systems, (Edited by F. Kreith, R. Boehm, J. Mitchell and R. Bannerot), ASME, New York, 1978.

22. Crowley, A. B., "Numerical Solution of Stefan Problems," Int. Journal of Heat and Mass Transfer, Vol. 21, pp. 215-219, 1978.

23. Ramachandran, N., Jaluria, Y., Gupta, J. P., "Thermal and Fluid Flow Characteristics In One-Dimensional Solidification," Letters in Heat and Mass Transfer, Vol. 8, pp. 6977, 1981.

24. Morgan, K., "A Numerical Analysis of Freezing and Melting With Convection," Computer Methods in Applied Mech. and Engr., Vol. 28, pp. 275-284, 1981.

25. Voller, V. R., and Cross, M., "Accurate Solutions of Moving Boundary Problems Using the Enthalpy Method," Int. Journal of Heat and Mass Transfer, Vol. 24, pp. 545556,1981 .

26. Voller, V. R., and Cross, M., "Estimating the Solidification/Melting Times of Cylindrically Symmetric Regions," Int. Journal of Heat and Mass Transfer, Vol. 24, No. 9, pp. 1457-1462, 1981. 
27. Gadgil, A., Gobin, D., "Analysis of Two-Dimensional Melting in Rectangular Enclosures in Presence of Convection," ASME Journal of Heat Transfer, Vol. 106, pp. 20-26, 1984.

28. Okada, M., "Analysis of Heat Transfer During Melting From a Vertical Wall," Int. Journal of Heat and Mass Transfer, Vol. 27, No. 11, pp. 2057-2066, 1984.

29. Bénard, C., Gobin, D., and Martinez, F., "Melting in Rectangular Enclosures: Experiments und Numerical Simulations," ASME Journal of Heat Transfer, Vol. 107, pp.794$803,1985$.

30. Voller, V. R., "Implicit Finite-Difference Solutions of the Enthalpy Forrnulation of Stefan Problems," IMA Journal of Numerical Analysis, Vol. 5, pp. 201-214, 1985.

31. Bénard, C., Gobin, D., and Zanoll, A., "Moving Boundary Problem: Heat Conduction in the Solid Phase of a Phase-Change Material During Melting Driven by Natural Convection in the Liquid," Int. Journal of Heat and Mass Transfer, Vol. 29, No. 11, pp. 1669-1681, 1986.

32. Voller, V. R., and Prakash, C., "A Fixed Grid Numerical Modelling Methodology for Convection-Diffusion Mushy Region Phase-Change Problems," Int. Journal of Heat and Mass Transfer, Vol. 30, No. 8, pp. 1709-1719, 1987.

33. Voller, V. R., Cross, M., and Markatos, N. C., "An Enthalpy Method for Convection/ Diffusion Phase Change," Int. Journal for Numerical Methods in Engr., Vol. 24, pp. 271 $284,1987$.

34. Bennon, W. D., and Incropera, F. P., "A Continuum Model for Momentum, Heat and Species Transport in Binary Solid-Liquid Phase Change Systems-1. Model Formulatior," Int. Journal of Heat and Mass Transfer, Vol. 30, No. 10, pp. 2161-2170, 1987.

35. Bennon, W. D., and Incropera, F. P., "A Continuum Model for Momentum, Heat and Species Transport in Binary Solid-Liquid Phase Change Systems-II. Application to Solidification in a Rectangular Cavity," Int. Journal of Heat and Mass Transfer, Vol. 30, No. 10, pp. 2171-2187, 1987.

36. Hsu, C. F., Sparrow, E. M., and Patankar, S. V., "Numerical Solution of Moving Boundary Problems by Boundary Immobilization and a Control-Volume-Based FiniteDifference Scheme," Int. Journal of Heat and Mass Transfer, Vol. 24, No. 8, pp. 1335 1343, 1981.

37. Cao, Y., Faghri, A. and Chang, W. S., "A Numerical Analysis of Stefan Problems For Generalized Multi-Dimensional Phase-Change Structures Using the Enthalpy Transforming Model," Int. Journal of Heat and Mass Transfer, Vol. 32, No. 7, pp. 1289-1298, 1989.

38. Voller, V. R., Brent, A. D., and Prakash, C., "The Modelling of Heat, Mass, and Solute Transport in Solidification Systems," Int. Journal of Heat and Mass Transfer, Vol. 32. No. 9, pp. 1719-1731, 1989. 
39. Patankar, S. V., Numerical Heat Transfer and Fluid Flow, Hemisphere Publishing, Washington D.C., 1980.

40. Incropera, F. P., and DeWitt, D. P., Introduction to Heat Transfer. John Wiley and Sons, Inc., New York, 1985.

41. Özisik, M. N., Heat Conduction, John Wilev and Sons, Inc., New York, 1980.

\section{APPENDIX}

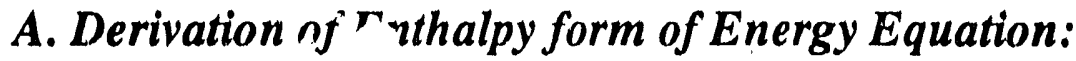

Conservation of energy may be expressed as

$$
\dot{E}_{S T}=\dot{E}_{A D V}+\dot{E}_{C O N D}+\dot{W}_{N E T}+\dot{E}_{G}
$$

where:

$$
\begin{aligned}
& \dot{E}_{S T}=\text { Rate of energy stored }=\rho \frac{\partial h}{\partial t} \text { (see note below) } \\
& \dot{E}_{A D V}=\text { Rate of energy advected by bulk fluid motion }=-\rho\left(u \frac{\partial h}{\partial x}+v \frac{\partial h}{\partial y}\right) \\
& \dot{E}_{C O N D}=\text { Rate of energy conducted }=k \nabla^{2} T=\frac{k}{c} \nabla^{2} h, \text { since } h=c T \\
& \dot{W}_{N E T}=\text { Rate of work done on fluid }=\Phi=0 \quad \text { (viscous dissipation, neglected for } \\
& \dot{E}_{G}=\text { Rate of energy absorbed = Latent heat sink term. }
\end{aligned}
$$

Note that internal energy may be expressed as $e=h-P v$ and $\frac{\partial e}{\partial t}=\frac{\partial h}{\partial t}-\frac{\partial}{\partial t} P v$. Assuming an incompressible fluid and negligible volume change upon melting, the second term, $-\frac{\partial}{\partial t} P v$ is zero, therefore the internal energy may be expressed in terms of enthalpy.

Assuming constant material properties, equation (1) may be written as

$$
\frac{\partial h}{\partial t}+u \frac{\partial h}{\partial x}+\nu \frac{\partial h}{\partial y}=\frac{\dot{E}_{G}}{\rho}+\alpha \nabla^{2} h
$$

where $\alpha=\frac{k}{\rho c}$. 
Next, $\dot{E}_{G}$, the latent heat source term, is derived.

The total enthalpy can be defined as the sum of the sensible enthalpy, $h$, and the latent heat, $\Delta H$;

$$
H=h+\Delta H \text {. }
$$

Note that for isothermal melting, the value of the latent heat absorbed is

$$
\Delta H=F(T)=\left\{\begin{array}{ll}
L, & \left(T>T_{m}\right) \\
0, & \left(T<T_{m}\right)
\end{array} .\right.
$$

Taking an energy balance over a volume undergoing a phase change yields

$$
\frac{d}{d t} \int_{V} \rho H d V=\int_{S}-\rho H(\boldsymbol{u} \cdot \boldsymbol{n}) d S+\int_{S} k(\nabla T \cdot \boldsymbol{n}) d S
$$

where $u$ here is a general velocity term in all directions.

Applying the divergence theorem to equation (5)

$$
\int\left\{\rho \frac{\partial H}{\partial t}+\operatorname{div}(H \rho u)-\operatorname{div}(k \nabla T)\right\} d V=0
$$

or since $\mathrm{V}$ is arbitrary

$$
\rho \frac{\partial H}{\partial t}+\operatorname{div}(H \rho \boldsymbol{u})-\operatorname{div}(k \nabla T)=0
$$

Substituting equation (3) into (6), assuming $\mathrm{k}$ and $\rho$ are constant, noting that $h=c T$ and rearranging yields

$$
\frac{\partial h}{\partial t}+\frac{\partial}{\partial t} \Delta H+\operatorname{div}(h u)+\operatorname{div}(\Delta H u)-\alpha \nabla^{2} h=0
$$

Expanding equation (7)

$$
\begin{aligned}
& \frac{\partial h}{\partial t}+\frac{\partial}{\partial t} \Delta H+h\left(\frac{\partial u}{\partial x}+\frac{\partial v}{\partial y}\right)+u\left(\frac{\partial h}{\partial x}+\frac{\partial h}{\partial y}\right)+ \\
&(\Delta H)\left(\frac{\partial u}{\partial x}+\frac{\partial v}{\partial y}\right)+u\left(\frac{\partial}{\partial x} \Delta H+\frac{\partial}{\partial y} \Delta H\right)-\alpha \nabla^{2} h=0
\end{aligned}
$$


However, from continuity,

$$
\frac{\partial u}{\partial x}+\frac{\partial v}{\partial y}=0
$$

Therefore equation ( 7 ) reduces to

$$
\frac{\partial h}{\partial t}+\frac{\partial}{\partial t} \Delta H+u\left(\frac{\partial h}{\partial x}+\frac{\partial h}{\partial y}\right)+u\left(\frac{\partial}{\partial x} \Delta H+\frac{\partial}{\partial y} \Delta H\right)-\alpha \nabla^{2} h=0
$$

However, for isothermal phase change (the limiting case of phase change over a temperature range), $u=0$ at the solid-liquid interface due to the no-slip condition where $\Delta H$ changes from 0 to L. Equation (9) then reduces to

$$
\frac{\partial h}{\partial t}+\frac{\partial}{\partial t} \Delta H+u \frac{\partial h}{\partial x}+v \frac{\partial h}{\partial y}=\alpha \nabla^{2} h
$$

Comparing equation (10) to (2), the latent heat source term is

$$
\dot{E}_{G}=-\rho \frac{\partial}{\partial t} \Delta H
$$

Neglecting convection in equation (10) yields

$$
\frac{\partial h}{\partial t}+\frac{\partial}{\partial t} \Delta H=\alpha \nabla^{2} h
$$

This equation may be written as

$$
\frac{1}{\alpha}\left(\frac{\partial h}{\partial t}+\frac{\partial}{\partial t} \Delta H\right)=\frac{\partial^{2} h}{\partial x^{2}}+\frac{\partial^{2} h}{\partial y^{2}}
$$

which in terms of dimensionless variables becomes

$$
\frac{\partial}{\partial F o} h^{*}+\frac{\partial}{\partial F o} \Lambda^{*}=(f)^{2} \frac{\partial^{2}}{\partial \xi^{2}} h^{*}+\frac{\partial^{2}}{\partial \eta^{2}} h^{*}
$$




\section{B. Discretization of Enthalpy form of Energy Equation:}

Recall equation (11) from Appendix Part A

$$
\frac{\partial}{\partial F_{o}} h^{*}+\frac{\partial}{\partial F_{o}} \Delta H^{*}=()^{2} \frac{\partial^{2}}{\partial \xi^{2}} h^{*}+\frac{\partial^{2}}{\partial \eta^{2}} h^{*}
$$

Central-difference approximations to the spatial derivatives and backward-difference approximations to the time derivatives are used to discretize equation (13).

Let $t=p \Delta t, \Delta F o=\frac{\alpha \Delta t}{a^{2}}, \Delta \xi=\frac{f \Delta x}{a}$ and $\Delta \eta=\frac{\Delta y}{a}$, then

the partial derivative approximations are:

$$
\begin{gathered}
\left.\frac{\partial}{\partial F o} h^{*}\right|_{m, n} \approx \frac{h_{m, n}^{* p+1}-h_{m, n}^{* p}}{\Delta F o} \\
\left.\frac{\partial}{\partial F o} \Delta H^{*}\right|_{m, n} \approx \frac{\Delta H_{m, n}^{* p+1}-\Delta H_{m, n}^{* p}}{\Delta F o} \\
\left.\frac{\partial^{2}}{\partial \xi^{2}} h^{*}\right|_{m, n} \approx \frac{h_{m+1, n}{ }^{* p+1}+h_{m-1, n}^{* p+1}-2 h_{m, n}^{* p+1}}{(\Delta \xi)^{2}} \\
\left.\frac{\partial^{2}}{\partial \eta^{2}} h^{*}\right|_{m, n} \approx \frac{h_{m, n+1}^{* p+1}+h_{m, n-1}^{*{ }^{*}+1}-2 h_{m, n}^{* p+1}}{(\Delta \eta)^{2}} .
\end{gathered}
$$

Substituting equations (14), (15), (16), and (17) into (13) yields

$$
\begin{aligned}
\left(\frac{h_{m, n}^{* p+1}-h_{m, n}^{* p}}{\Delta F o}+\right. & \left.\frac{\Delta H_{m, n}^{* p+1}-\Delta H_{m, n}^{* p}}{\Delta F o}\right) \\
= & (f)^{2}\left(\frac{h_{m+1, n}^{* p+1}+h_{m-1, n}^{* p+1}-2 h_{m, n}^{* p+1}}{(\Delta \xi)^{2}}\right) \\
& +\left(\frac{h_{m, n+1}^{* p+1}+h_{m, n-1}^{* p+1}-2 h_{m, n}^{* p+1}}{(\Delta \eta)^{2}}\right)
\end{aligned}
$$


Therefore, the implicit form of the finite-difference equation for an interior node $m, n$ is

$$
\begin{aligned}
& h_{m, n}{ }^{* p}=\Delta H_{m, n}{ }^{*}{ }^{* p+1}-\Delta H_{m, n}{ }^{*}+\left(1+\frac{2(f)^{2} \Delta F o}{(\Delta \xi)^{2}}+\frac{2 \Delta F o}{(\Delta \eta)^{2}}\right) h_{m, n}{ }^{{ }^{*} p+1} \\
& -\frac{\left(f^{2} \Delta F o\right.}{(\Delta \xi)^{2}}\left(h_{m+1, n}{ }^{* p+1}+h_{m-1, n}{ }^{* p+1}\right)-\frac{\Delta F o}{(\Delta \eta)^{2}}\left(h_{m, n+1}{ }^{* p+1}+h_{m, n-1}{ }^{* p+1}\right) .
\end{aligned}
$$

Finite-difference equations for the boundary nodes are derived in a similar fashion, and are listed below and on the following page. Equations are included for both programs. For more information see [39-41].

Boundary nodes at $x=0$ with boundary condition of the first kind (prescribed temperature):

$$
h_{m, n}{ }^{{ }_{p} p}=C .
$$

Boundary nodes at $\mathrm{x}=0$ with boundary condition of the second kind (constant heat flux):

$$
\begin{aligned}
h_{m, n}{ }^{{ }_{p}}= & \Delta H_{m, n}{ }^{{ }_{p}+1}-\Delta H_{m, n}{ }^{{ }_{p}}+\left(1+\frac{2(f)^{2} \Delta F o}{(\Delta \xi)^{2}}+\frac{2 \Delta F o}{(\Delta \eta)^{2}}\right) h_{m, n}{ }^{{ }_{p+1}} \\
& -\frac{2(f)^{2} \Delta F o}{(\Delta \xi)^{2}}\left(q^{*}+h_{m+1, n}{ }^{{ }_{p}+1}\right)-\frac{\Delta F o}{(\Delta \eta)^{2}}\left(h_{m, n+1}{ }^{{ }_{p}+1}+h_{m, n-1}{ }^{*_{p+1}}\right) .
\end{aligned}
$$

Boundary nodes at $\mathrm{x}=\mathrm{b}$ with boundary condition of the second kind (insulated):

$$
\begin{aligned}
& h_{m, n}{ }^{{ }_{p}}{ }^{2}=\Delta H_{m, n}{ }^{*_{p+1}}-\Delta H_{m, n}{ }^{{ }_{p} p}+\left(1+\frac{2(f)^{2} \Delta F o}{(\Delta \xi)^{2}}+\frac{2 \Delta F o}{(\Delta \eta)^{2}}\right) h_{m, n}{ }^{*_{p+1}} \\
& -\frac{2(f)^{2} \Delta F o}{(\Delta \xi)^{2}}\left(h_{m-1, n}{ }^{* p+1}\right)-\frac{\Delta F o}{(\Delta \eta)^{2}}\left(h_{m, n+1}{ }^{* p+1}+h_{m, n-1}{ }^{* p+1}\right) .
\end{aligned}
$$

Corner node at $x=0, y=a$ with boundary conditions of the second kind (constant heat flux at $x=0$ and insulated at $y=a$ ):

$$
\begin{aligned}
h_{m, n}{ }^{* p}=\Delta H_{m, n}{ }^{{ }_{p}+1}-\Delta H_{m, n}{ }^{* p}+\left(1+\frac{2(f)^{2} \Delta F o}{(\Delta \xi)^{2}}+\frac{2 \Delta F o}{(\Delta \eta)^{2}}\right) h_{m, n}{ }^{* p+1} \\
-\frac{2(f)^{2} \Delta F o}{(\Delta \xi)^{2}}\left(q^{*}+h_{m+1, n}{ }^{*_{p+1}}\right)-\frac{2 \Delta F o}{(\Delta \eta)^{2}}\left(h_{m, n-1}{ }^{{ }^{p}+1}\right) .
\end{aligned}
$$


Corner node at $x=b, y=a$ with boundary conditions of the second kind (insulated at $x=b$ and insulated at $y=a)$ :

$$
\begin{aligned}
h_{m, n}{ }^{* p}=\Delta H_{m, n}{ }^{* p+1} & -\Delta H_{m, n}{ }^{* p}+\left(1+\frac{2(f)^{2} \Delta F o}{(\Delta \xi)^{2}}+\frac{2 \Delta F o}{(\Delta \eta)^{2}}\right) h_{m, n}{ }^{* p+1} \\
& -\frac{2(f)^{2} \Delta F o}{(\Delta \xi)^{2}}\left(h_{m-1, n}{ }^{* p+1}\right)-\frac{2 \Delta F o}{(\Delta \eta)^{2}}\left(h_{m, n-1}^{* p+1}\right) .
\end{aligned}
$$

The preceding finite-difference equations are expressed in a convenient form, however prior to coding, they have been rearranged to solve for $h_{m, n}{ }^{* p+1}$.

For problems involving a boundary condition of the third kind, i.e. convection, the boundary finite-difference equation may be discretized in the same manner and inserted into the code. Thus, the FORTRAN programs listed on the following pages may be adapted to handle any sort of Stefan problem in a rectangular region.

\section{Determination of Aluminum Enhanced PCM Thermal Conductivity:}

Assuming that the aluminum honeycomb structure is aligned as fins in the direction of heat flow, i.e. the x-direction, and that it occupies $10 \%$ of the total volume of the cavity, the thermal conductivity for one-dimensional steady-state heat transfer may be determined as two composite materials in parallel. Although the concern here is with transient heat transfer, this approximation will be used to determine an enhanced thermal conductivity and following is a discussion of why this approach is valid.

The thermal resistance for conduction in the cavity is defined as

$$
R=\frac{b}{k A}
$$

Therefore, the thermal resistances for aluminum and paraffin are

$$
\begin{array}{ll}
\text { for aluminum } & R_{A l}=\frac{b}{k_{A} A_{A l}} \\
\text { and for paraffin } & R_{p}=\frac{b}{k_{p} A_{p}} .
\end{array}
$$

The total thermal resistance can now be defined as

or.

$$
\frac{1}{R_{10 t}}=\frac{1}{R_{A l}}+\frac{1}{R_{p}}
$$

$$
k_{t o t} A_{t o t}=k_{A l} A_{A l}+k_{p} A_{p}
$$


Dividing both sides by the total area yields

$$
k_{t o t}=k_{A l}\left(\frac{A_{A l}}{A_{t o t}}\right)+k_{p}\left(\frac{A_{p}}{A_{t o t}}\right)
$$

in which the total thermal conductivity is a sum of each material's thermal conductivity multiplied by their respective area ratio which is the same as a volume percentage since the lengths of the two materials are equal.

Thus, with $k_{A l}=177 \mathrm{~W} / \mathrm{m}^{\circ} \mathrm{C}$ [40] and $k_{p}=0.23 \mathrm{~W} / \mathrm{m}^{\circ} \mathrm{C}$, and assuming $10 \%$ of the cross-sectional area is occupied with aluminum,

$$
k_{\text {tot }}=(0.1) 177 \mathrm{~W} / \mathrm{m}^{\circ} \mathrm{C}+(0.9) 0.23 \mathrm{~W} / \mathrm{m}^{\circ} \mathrm{C}=17.91 \mathrm{~W} / \mathrm{m}^{\circ} \mathrm{C}
$$

This value appears in Table 1 under aluminum enhanced thermal conductivity.

Since this paper is a feasibility study for the use of PCM's in cooling electronic modules, this determination of improved thermal conductivity gives an approximation to be used with the developed numerical code. However, realistically, with aluminum fins extending into the paraffin PCM, melting would occur around the fins and a distinct melting front would not propagate through the cavity as modelled. This phenomenon is threedimensional and its analysis is beyond the scope of this paper. In such a system, more PCM should be melted quicker than without the honeycomb structure, thus absorbing more heat in a shorter period. Since absorbing more heat faster would only reduce the temperature excursion further, the author feels that the results presented in the application section give a conservative indication of the advantages of using a PCM. 


\section{Fortran Program Listings:}

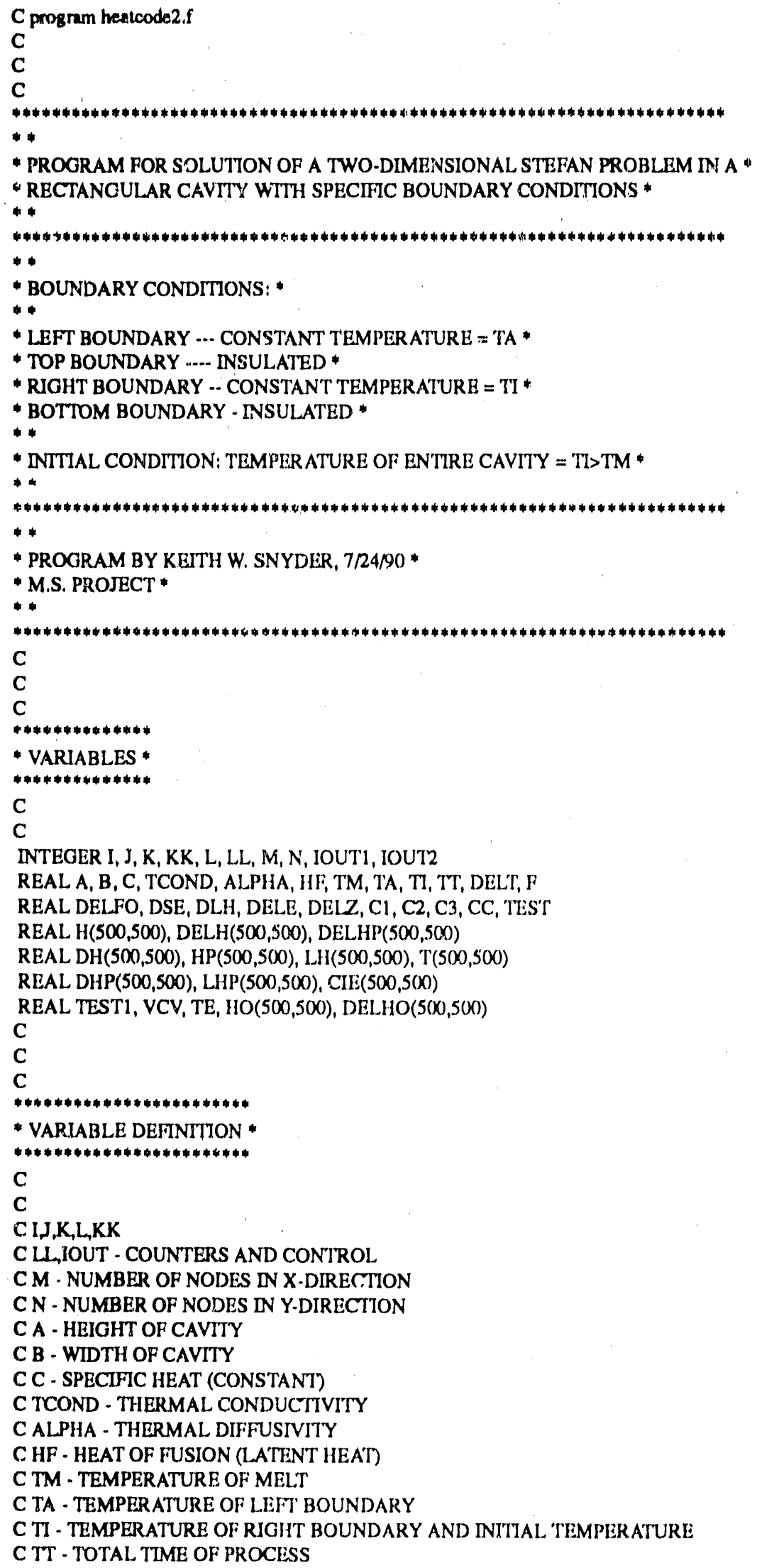




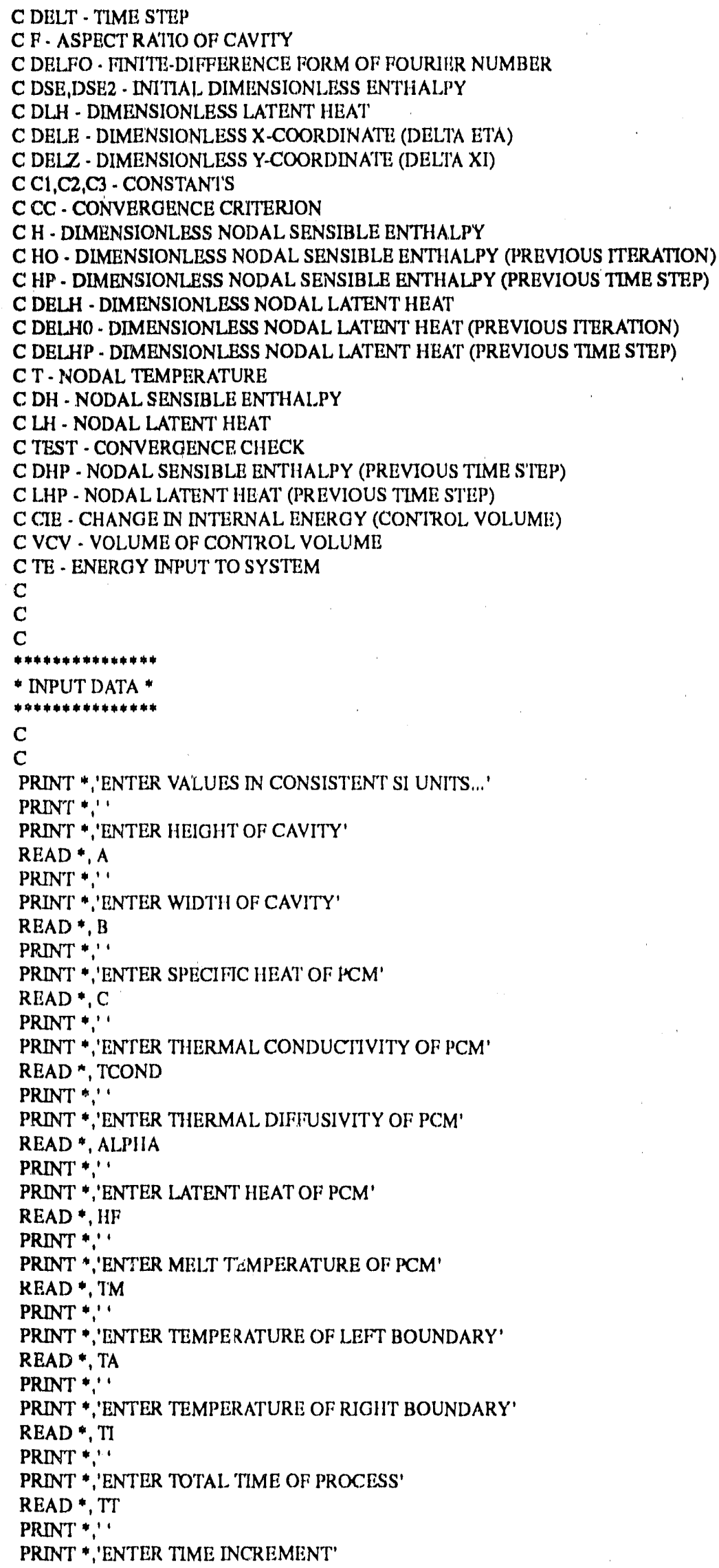




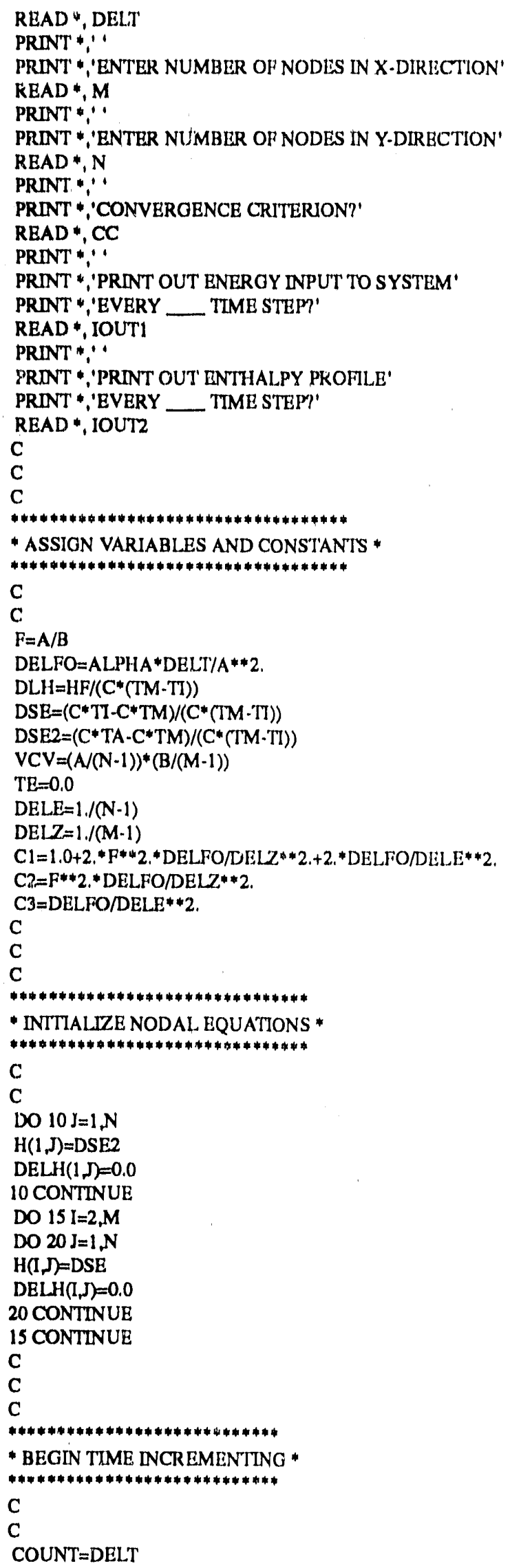




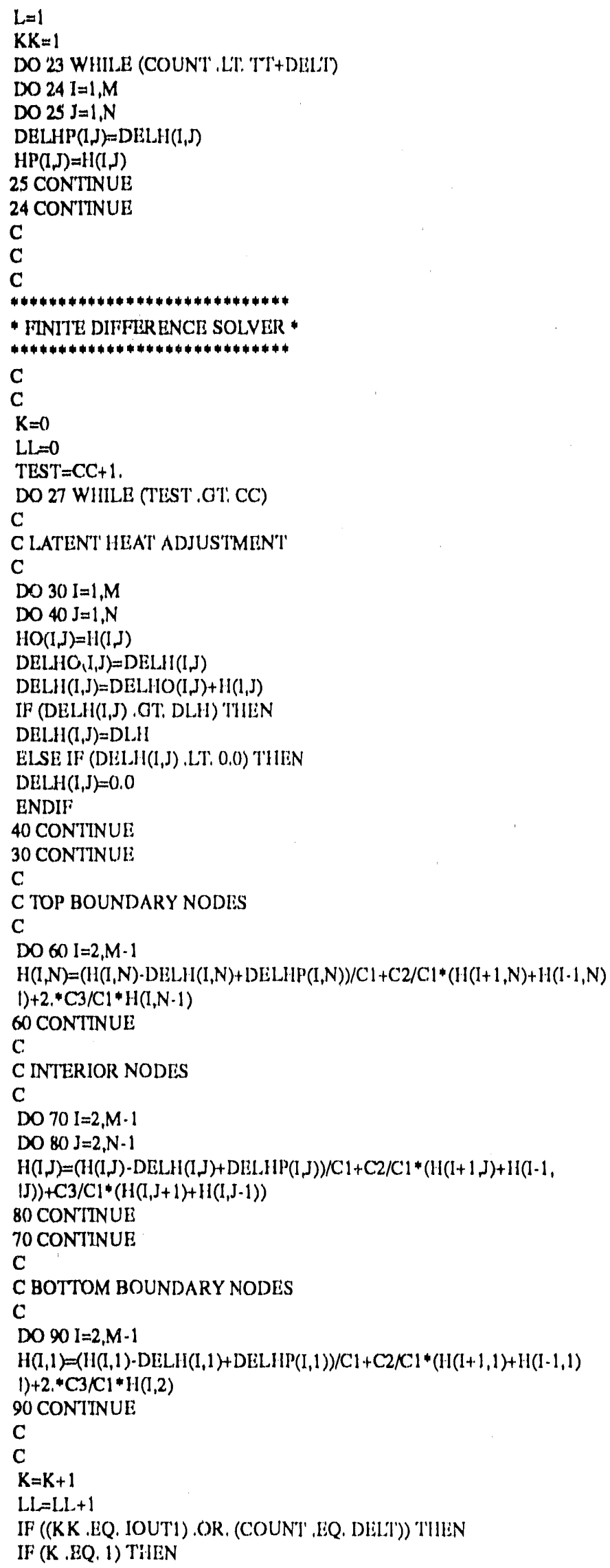




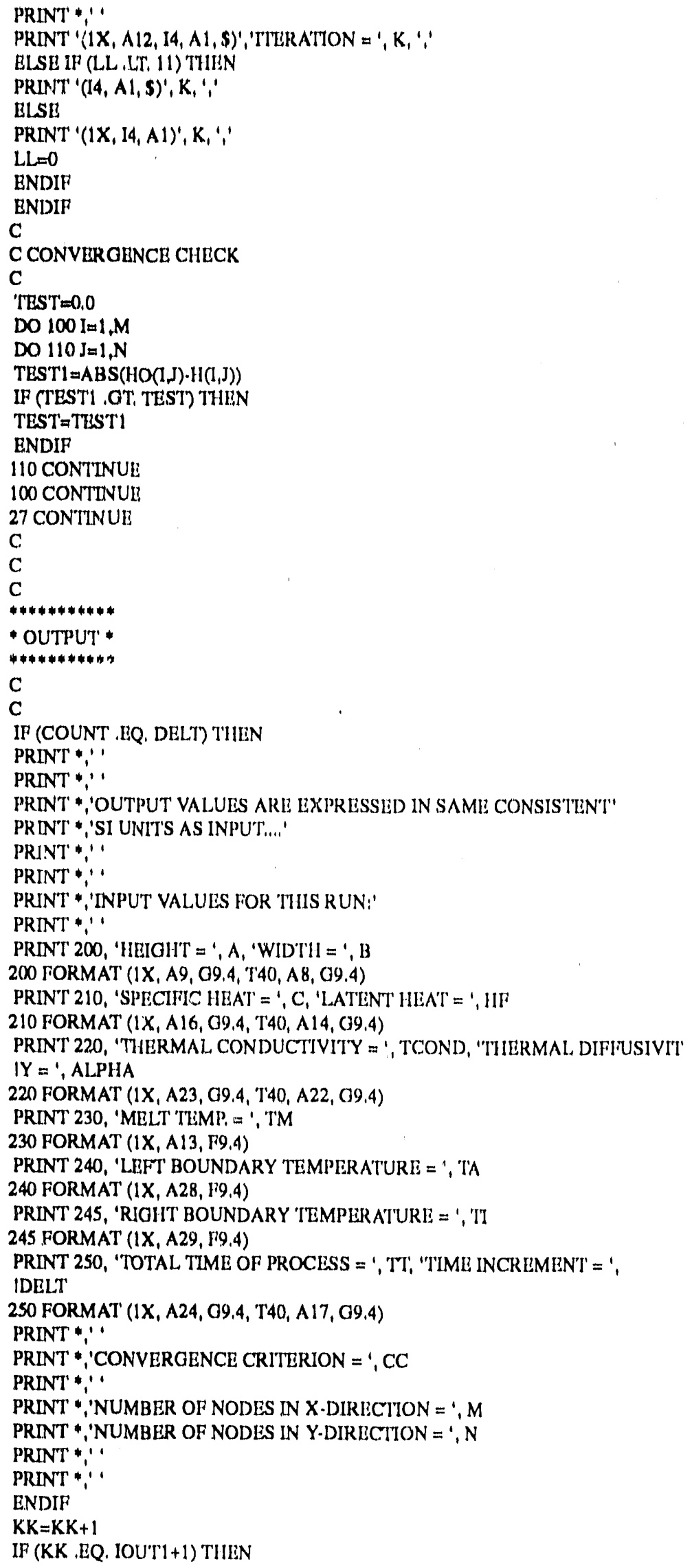




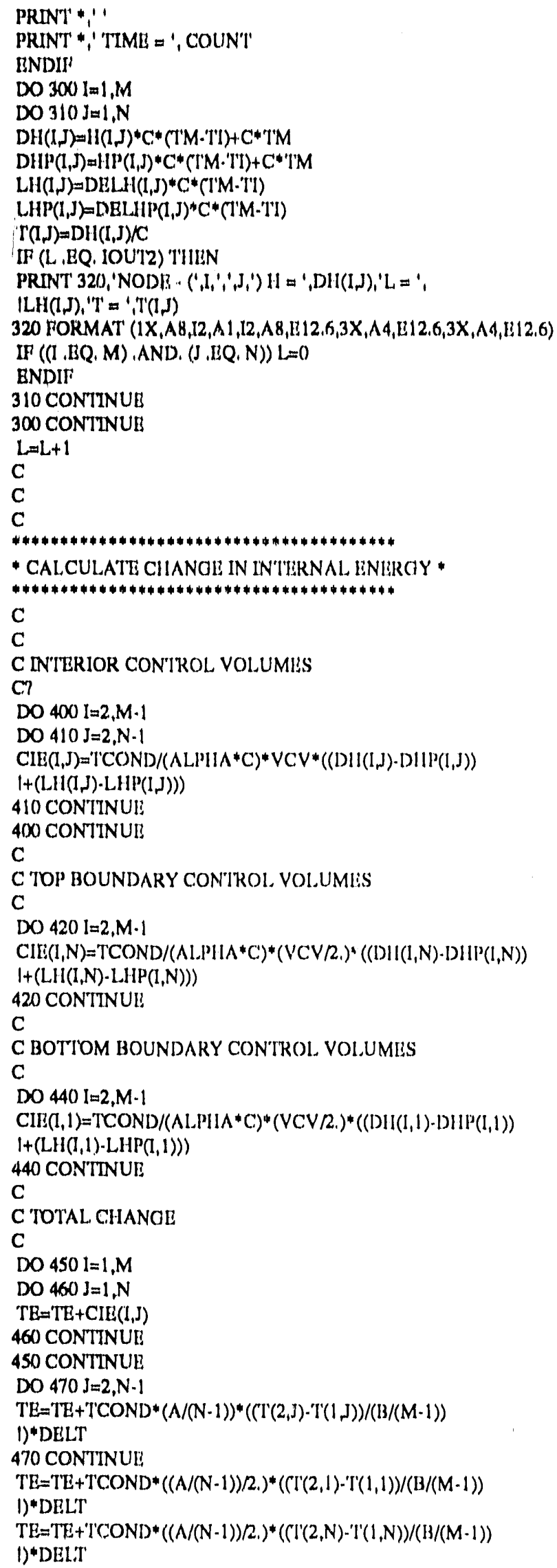


DO $480 J_{m=2}, N-1$

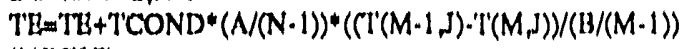

1)•DELT

480 CONTINUE

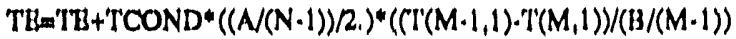

1)'DELT

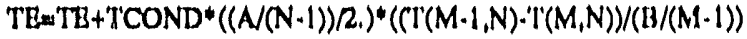

1) DERLT

IF (KK, BQ, IOUTI+1) THEN

PRINT *' BNEROY INPUT' 'IO SYSTEM = ', IT!

PRINT' " "

KKal

BNDIF

C

C

C

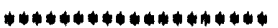

- INCREMENT' TIMI! *

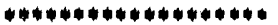

C

C

COUNT $=$ COUNT + DIULT'

23 CONTINUE

C

C

C

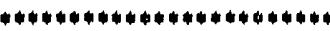

" PROCRAM TERMINATION *

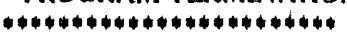

C

C

PRINT " "'

PRINT " $"$ "

PRINT *'TIME OF PROCISS COMPLEITID.....PROCIKAM 'TERMINATTED,'

C

STOP

END

C program heatcorlo.f

C

C

$\mathrm{C}$

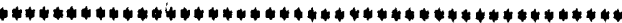

$*$ *

- program for solution op a two-dimbmisional stitifan problem in a *

" RECTANGUlar CAVITY WITHI SPILCIFIC bOUNDARY CONDItIIONS *

4

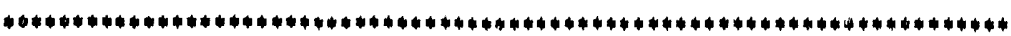

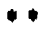

- boUNDARY CONDITIONS: *

* *

* left boundary ... constant iteát muX *

* top boundary .... INSUL A'Ttid *

" RIGHT BOUNDARY .. INSULA'TED *

- BOTTOM BOUNDARY - INSULATED *

*

- inITTAL CONDITTON: TBMPERa'TURb of en'TtRe CAVI'T'Y $=$ 'I'>'I'M *

*

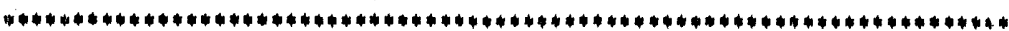

* 


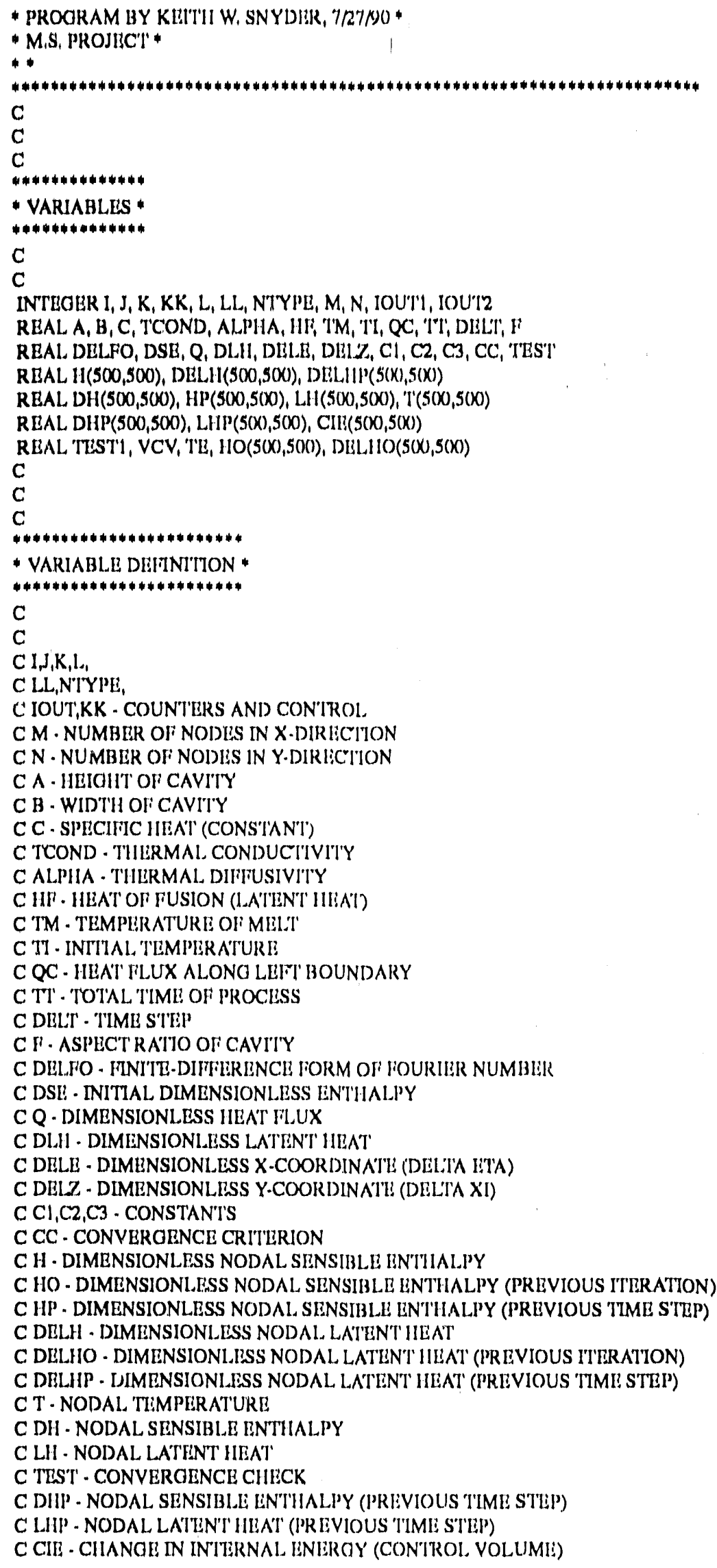




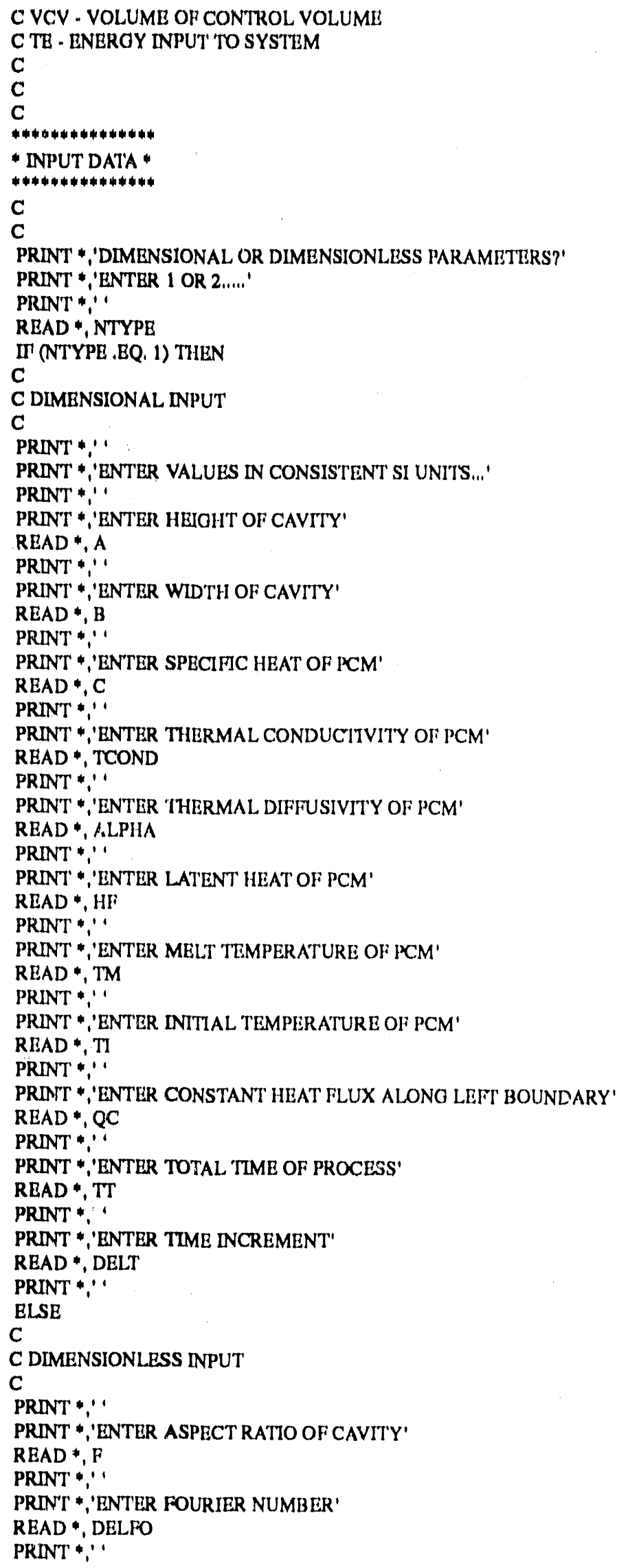


PRINT *'ENTER INTTIAL DIMENSIONLESS SENSIBLE ENTHALPY*

READ $\bullet$ DSE

PRINT * $\because$

PRINT ',ENTER DIMENSIONLESS HEAT FLUX ALONG LEFT BOUNDARY'

READ *, Q

PRINT $\because \cdots$

PRINT *'ENTER 1/STEFAN NUMBER'

READ * DLH

PRINT $\because$

PRINT *ENTER TOTAL TIME OF PROCESS

READ*,TT

ENDIF

PRINT *'ENTER NUMBER OF NODES IN X-DIRECTION'

READ*M $M$

PRINT $\because \cdots$

PRINT ' $\because E N T E R$ NUMBER OF NODES IN Y'DIRECTION"

READ * I

PRINT : $:$

PRINT "'CONVERGENCE CRITERION?'

READ *, CC

PRIT *

PRINT ".'PRINT OUT ENERGY INPUT TO SYSTEM"

PRINT *'EVERY 'TIME STEP?'

READ*, IOUTI

PRINT *

PRINT ' $\because$ PRINT OUT ENTHALPY PROFILE'

PRINT :EVERY TIME STEP?

READ * IOUT2

C

C

C

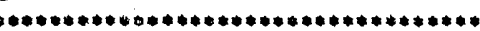

- ASSIGN VARIABLES aND CONSTANTS *

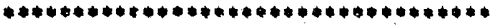

C

IF (NTYPE .EQ. 1) THEN

$\mathrm{Q}=\mathrm{QC} *\left(\mathrm{~B} /(\mathrm{M}-\mathrm{I} ;) /\left(T C O \mathrm{~N}^{*}(\mathrm{TM}-\mathrm{TI})\right)\right.$

$F=A / B$

$\mathrm{DELFO}=\mathrm{ALPHA} \cdot \mathrm{DELT} / \mathrm{A} * * 2$

$D L H=H F /(C *(T M-T T))$

DSE $=\left(C * T I-C^{*} T M\right) /(C *(T M-T I))$

$\mathrm{VCV}=(\mathrm{A} /(\mathrm{N}-1))^{*}(\mathrm{~B} /(\mathrm{M}-1))$

$\mathrm{TE}=0.0$

ENDIF

DELE $=1 . /(\mathbb{N}-1)$

DELZi=1.J(M-1)

$\mathrm{Cl}=1.0+2 . * \mathrm{~F}^{* * 2},{ }^{*} \mathrm{DELFO} / \mathrm{DELZ} * * 2 .+2 . * \mathrm{DELFO} / \mathrm{DELE} * * 2$

$\mathrm{C} 2=\mathrm{F} * * 2 . \cdot \mathrm{DELFO} D \mathrm{DEL} Z * * 2$

$C 3=$ DELFO $/ D E L F * 2$.

C

C

C

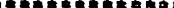

- INTTIALDZE NODAL EQUATIONS *

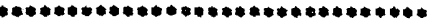

c

C

DO $10 I=1 M$

DO $20 \mathrm{~J}=1, \mathrm{~N}$

$H(I)=,D S E$

DELH(I.S) $=0.0$

CIE $(I)=$,

20 CONTINUE

10 CONTINLE 
C

C

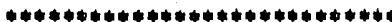

- BEGIN TIME INCREMENTING *

$* * * * * * * * * * * * * * * * * * * * * * * * * *$

C

C

IF (NTYPE .EQ. 1) THEN

COUNT $=$ DELT

ELSE

COUNT $=$ DELFO

ENDIF

$L=1$

$\mathrm{KK}=1$

DO 23 WHIIE (COUNT .LT. TT+DELT)

DO $24 \mathrm{I}=1, \mathrm{M}$

DO $25 \mathrm{~J}=1, \mathrm{~N}$

DELHP(I $)=$ DELH(I $)$

$H P(I)=,H(I$,

25 CONTINUE

24 CONTTNUE

C

C

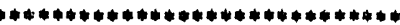

- FINTTE DIFFERENCE SOLVER *

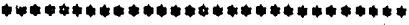

C

C

$K=0$

$L L=0$

TEST $=\mathrm{CC}+1$.

DO 27 WHILE (TEST .GT. CC)

C LATENT HEAT ADJUSTMENT

DO $30 \mathrm{I}=1, \mathrm{M}$

$\mathrm{DO} 40 \mathrm{~J}=1, \mathrm{~N}$

$H O(I J)=H(I J)$

DELHOO (I.J) $=$ DELH $(I$,

DELH $(I, J)=D E L H O(I J)+H(I, J)$

IF (DELH(I,J) .GT. DLH) THEN

DELHi(I,J)=DLH

ELSE IF (DELH(1,J) .LT. 0.0) THEN

DELH(I, 0.0

ENDIF

40 CONTINUE

30 CONTINUE

C

C LEFT BOUNDARY NODES

C

DO $50 \mathrm{~J}=2 \mathrm{~N}-1$

$H(1)=,(H(1, J)-D E L H(1, J)+D E L H O(1, J)) / C 1+2 . * C 2 / C 1 *(Q+H(2, J))+C 3 / C$

$11 *(\mathrm{H}(1 \mathrm{~J}+1)+\mathrm{H}(1 \mathrm{~J}-1))$

SO CONTINUE

C

C TOP \& BOTIOM LEFT CORNER NODES

C

$H(1, N)=(H(1, N)-D E L H(1, N)+D E L H O(1, N)) / C 1+2 . * C 2 / C 1 *(Q+H(2, N))+2 . * C 3 /$

ICI* $\mathrm{H}(1, \mathrm{~N}-1)$

$\mathrm{H}(1,1)=(\mathrm{H}(1,1)-\mathrm{DELH}(1,1)+\mathrm{DELHO}(1,1)) / \mathrm{C} 1+2 .{ }^{*} \mathrm{C} 2 / \mathrm{Cl}^{*}(\mathrm{Q}+\mathrm{H}(2,1))+2 .{ }^{*} \mathrm{C} 3 /$

ICl* $\mathrm{H}(1,2)$

C

C TOP \& BOTTOM BOUNDARY NODES 


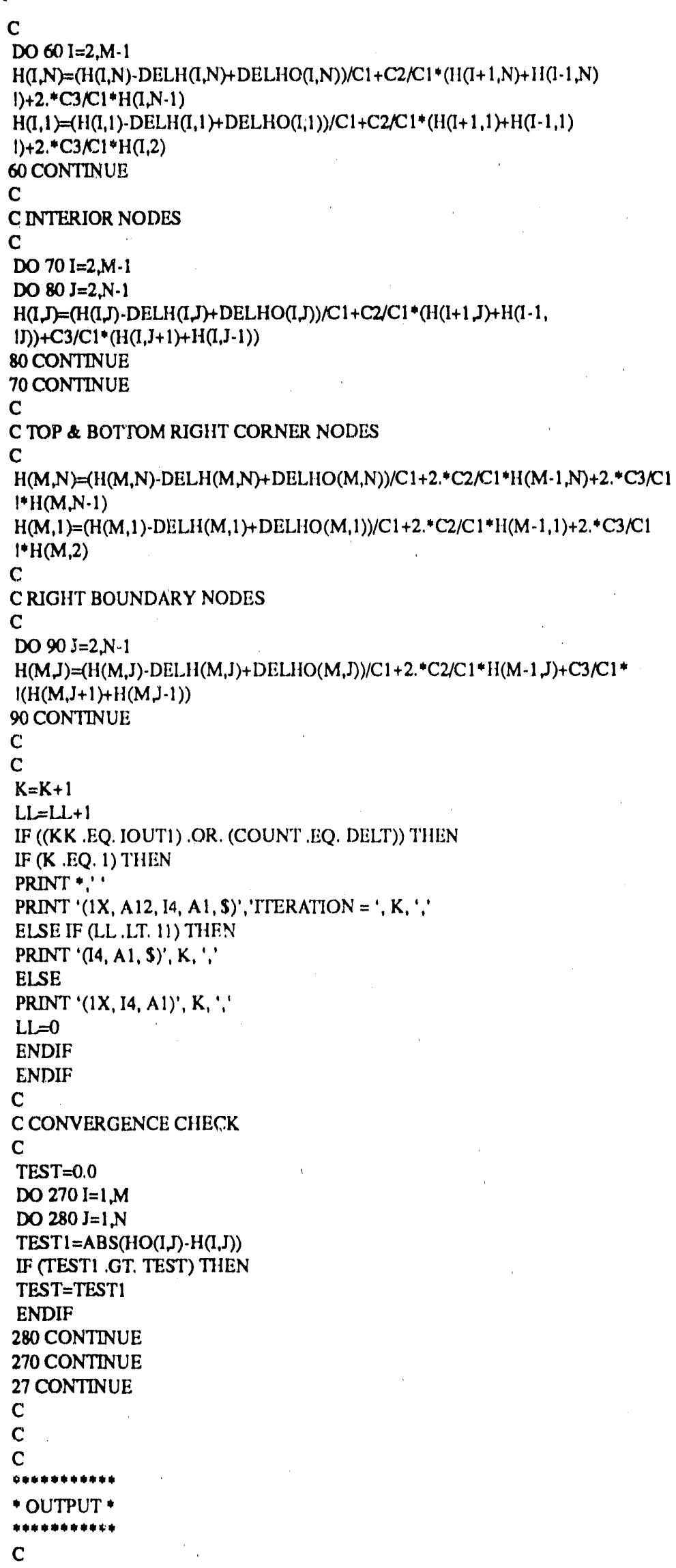




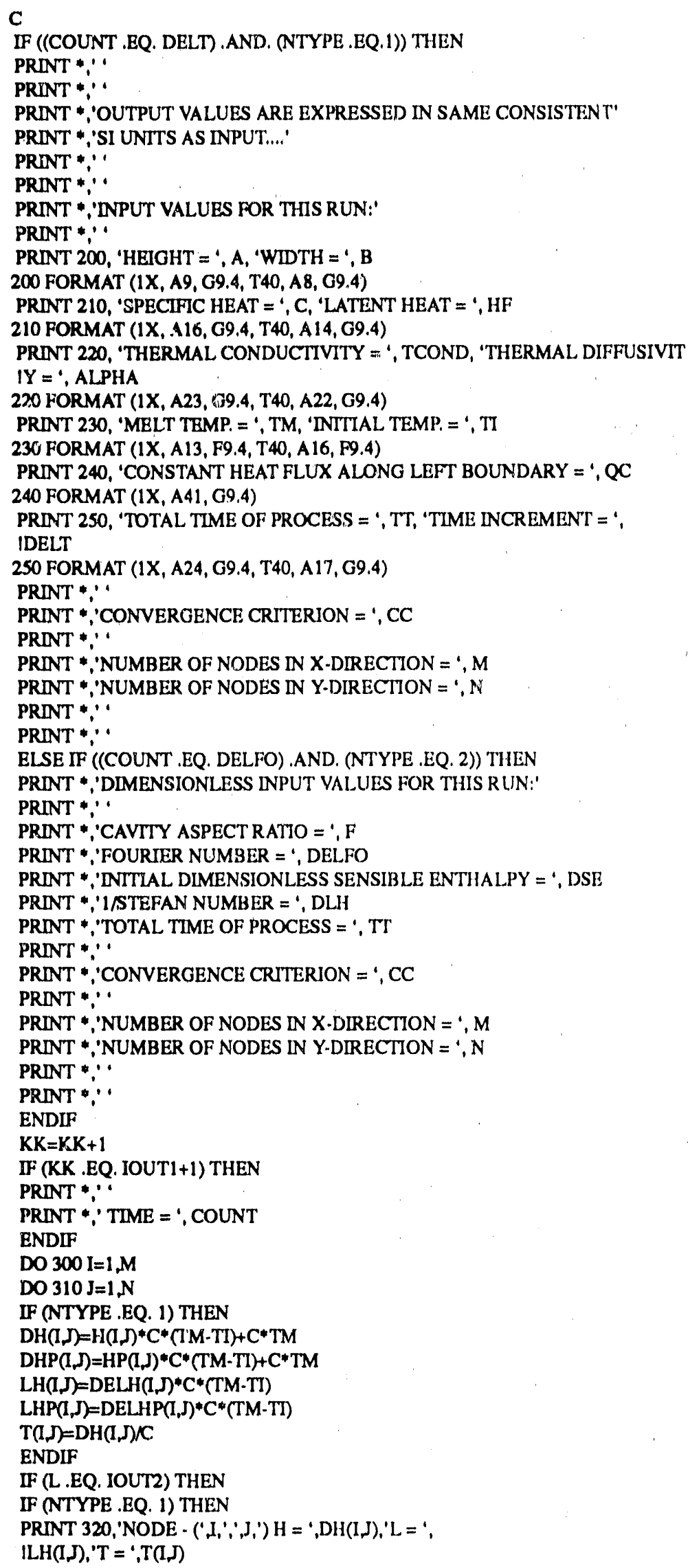




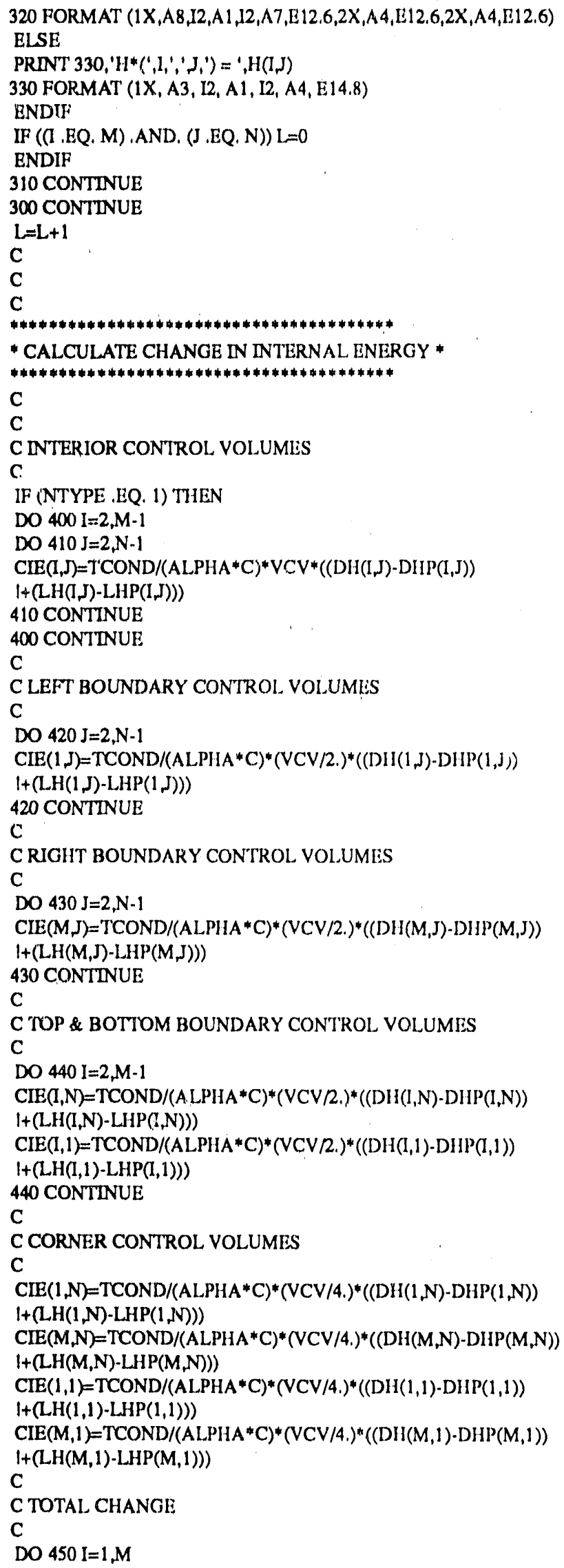




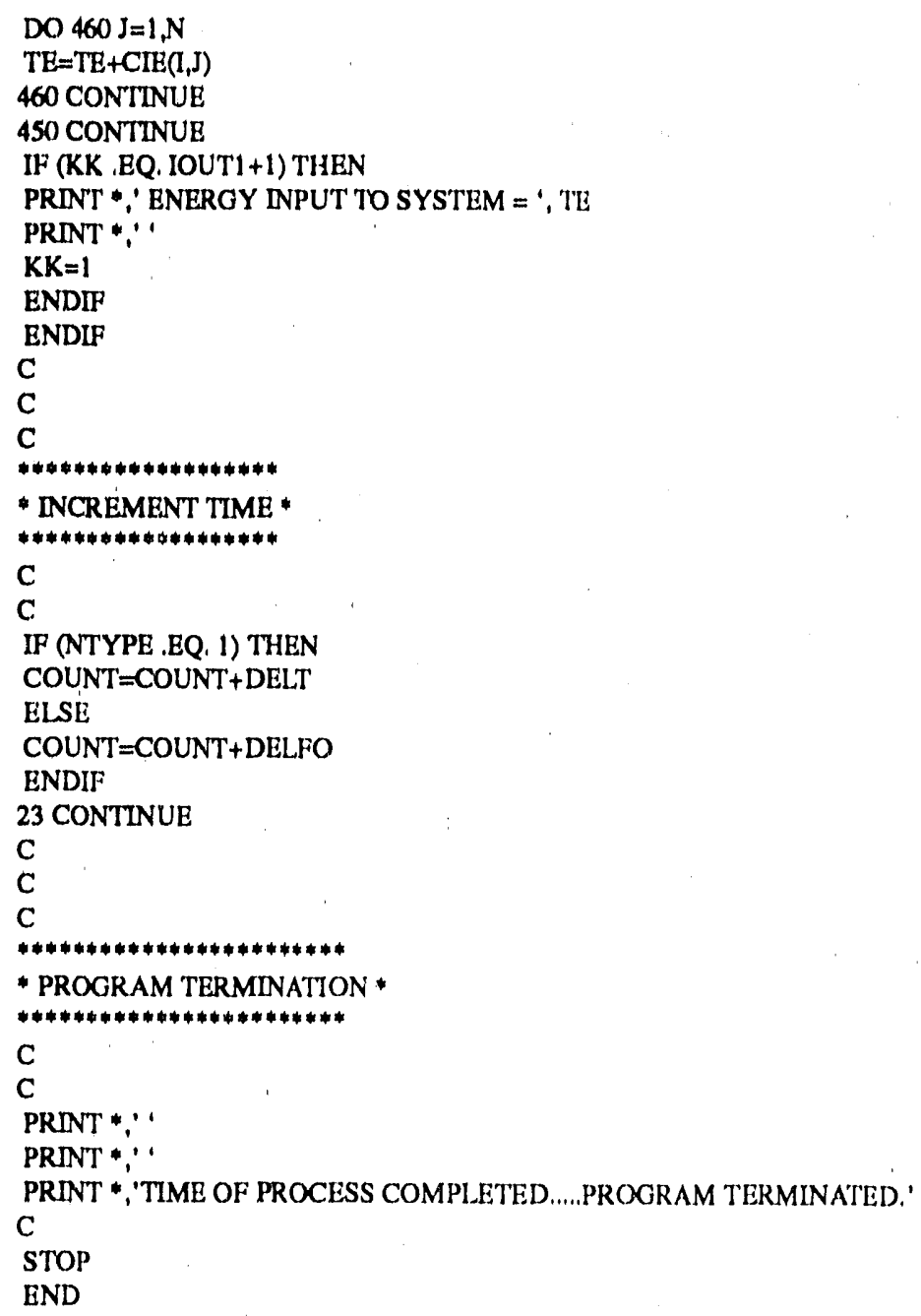



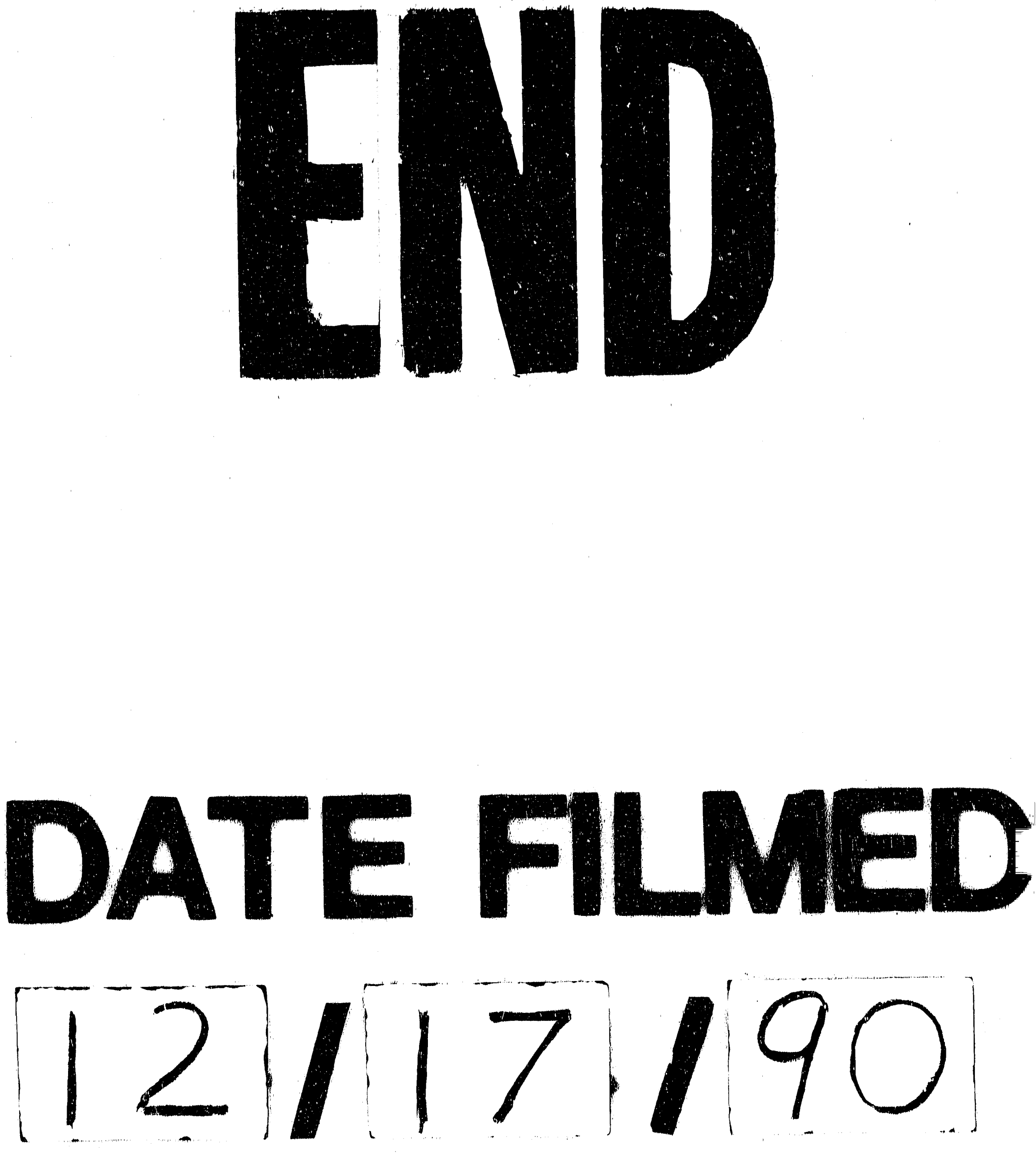
